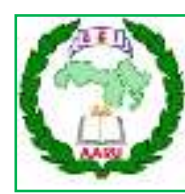

مجلة اتحاد الجامعات العربية للعلوم الزراعية، جامعة عين شمس، القاهرة، مصر

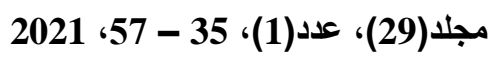

Website: http://ajs.journals.ekb.eg

DOI: 10.21608/ajs.2020.42469.1256

تحليل اقتصادي قياسي لمحددات صناعة سكر القصب في مصر

[3]

كريمة محمد محمود الصغير" - سلوى محمد أحمد عبد المنعم - محمد سيد شحاته

قسم الاقتصاد الزراعي - كلية الزراعة - جامعة عين شمس - ص.ب 68 - حدائق شبرا 11241 - القاهرة - مصر

${ }^{*}$ Corresponding author: dr.karima2020@gmail.com

Received 10 September, 2020

Accepted 20 February, 2021

الدراســة، فهى معنوية وذات إثـارة سـالبة، كما هو

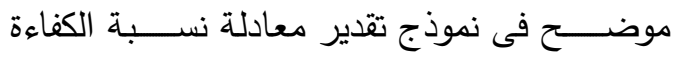

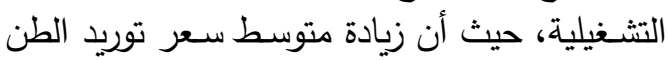
من القصب بنسبة 10\% سوف يؤدى إلى إنخفاض الكفاءة التشغيلية بمعدل بلغ نحو 3ن 3.11\%.

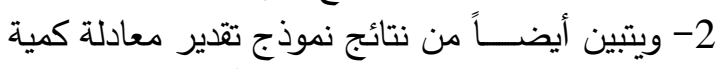

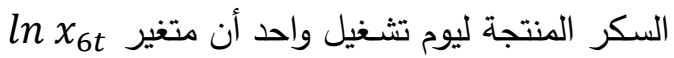

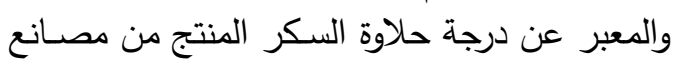

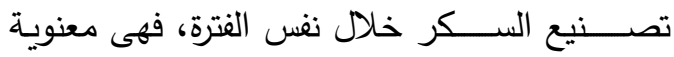

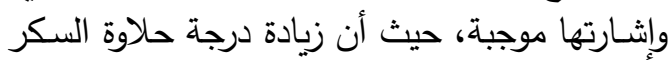

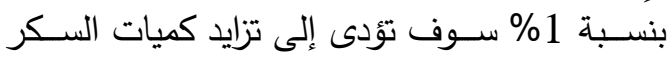

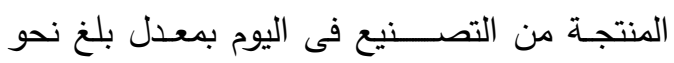
.\%19.6

3- ويتضــــح من مقاييس الكفاءة الاقتصــــادية لإنتاج

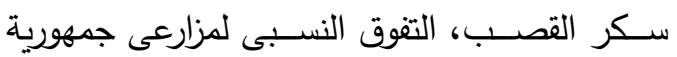

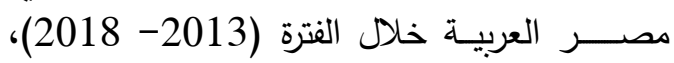

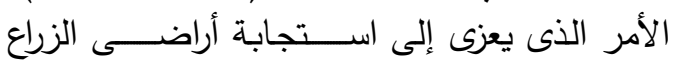

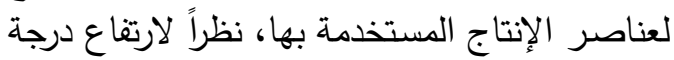

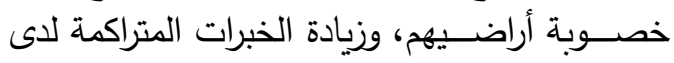

الزراع.

الكلمات المفتاحية: قصس السكر ، الكفاءة الاقتصسادية، نموذج بيانات الألواح، كفاءة التشغيل

\section{1}

يُُـــــد السـكر ســلعة زراعية صـــاعية ذات أهمية

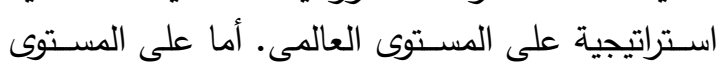

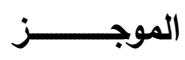

يُـــــد السـكر سـلعة زراعية صـنـاعية ذات أهمية

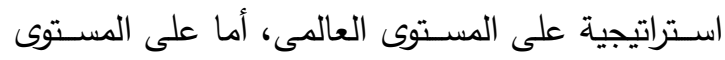

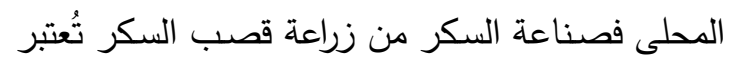

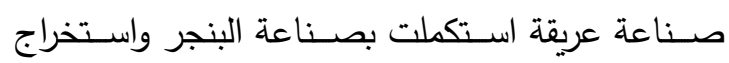

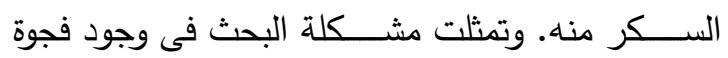

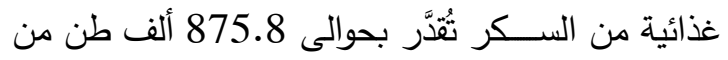
السكر كمتوسط سنوى للفترة (2000 - 2018)، ولسد السد

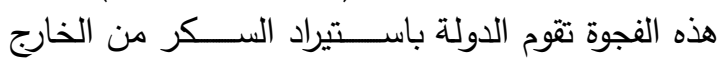

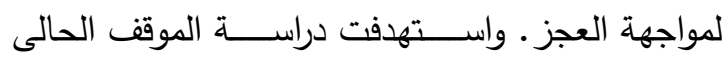

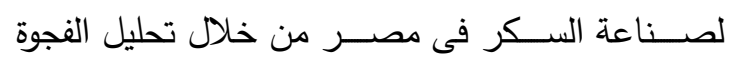

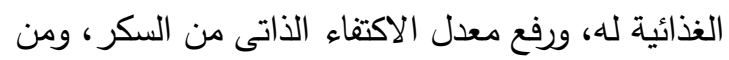

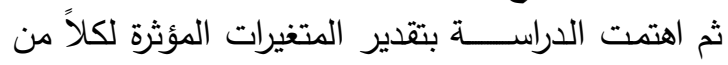

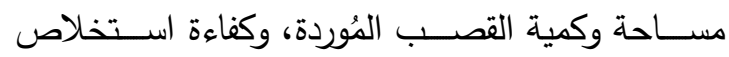
السكر على دالة كفاءة التثـغيل لمصسانع تصـنيع سكر القصب فى المحافظات الرئيسية وهى (المنيا، سوهاج، قنا، الأقصـر ، وأسـوان)، خلال متوسط الفترة (20162018)، وبـالمثل يمكن تقدير هذه والهـ المتغيرات المؤثرة

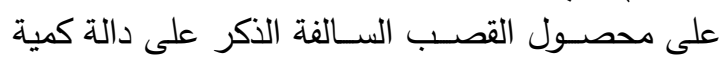

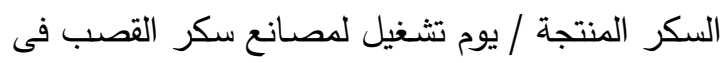

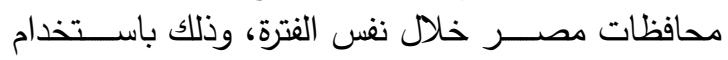
تحليل أسلوب Panel Data .

وأوضحت أهم نتائج الاراسة مايلى

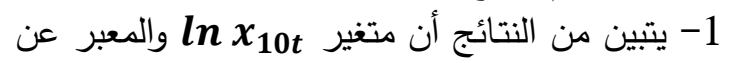

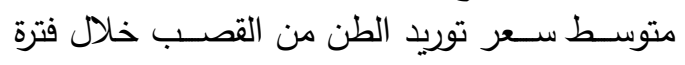


عن طريق التوســـع فى زراعة البنجر فى الأراضـــى

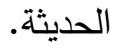

\section{3 هدف الدراسة}

تستهدف هذه الدراسة بوجه عام، إلى دراسة الموقف

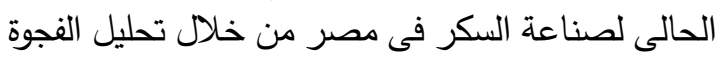
الغذائية منه، والتعرف على أبعادها، والتتبؤ بتطورها

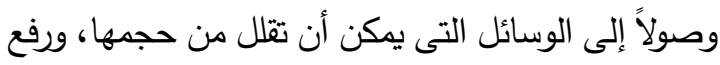

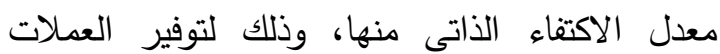
الصعبة التى تتفق على استيراد هذه السلعة الاستراتيجية الألى

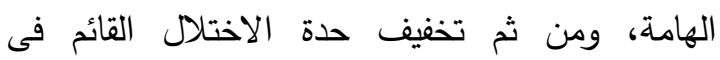

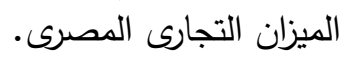

\section{4 الطريقة البحثية وطرق جمع البيانات}

يعتمد البحث على اســـــــام أســلـوبي التحليل

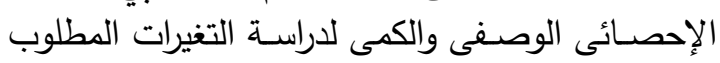

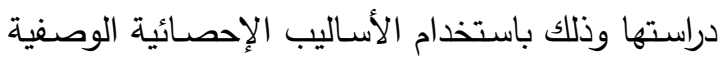

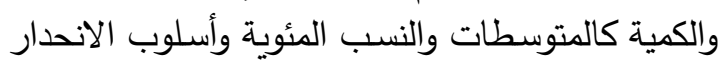

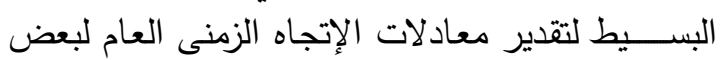

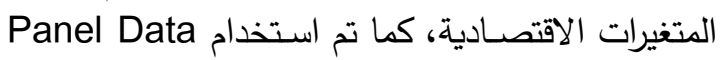

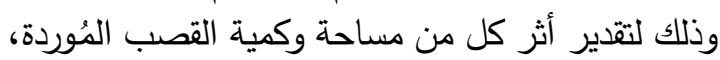

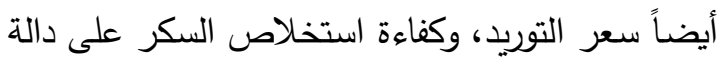

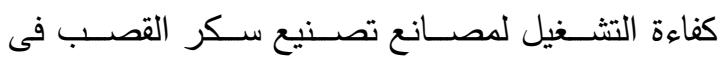

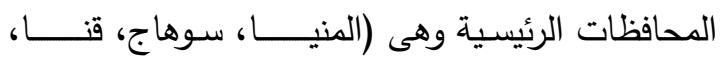

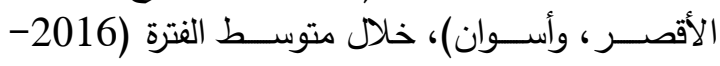

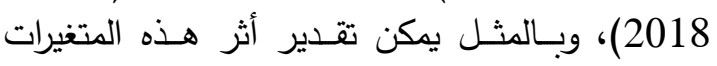

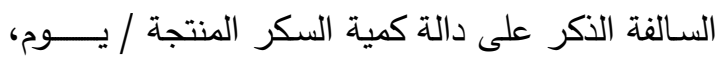

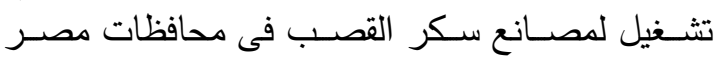
خلال نفس الفترة.

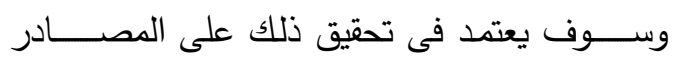

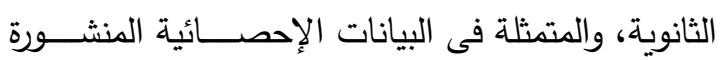

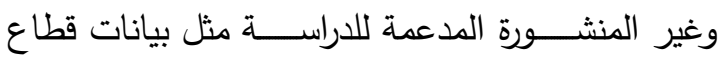

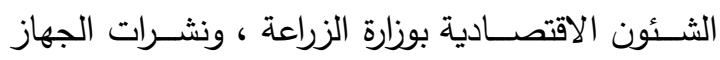

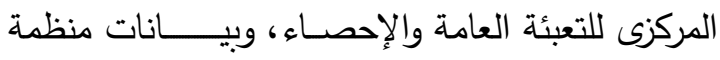

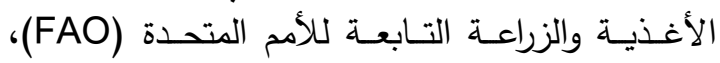

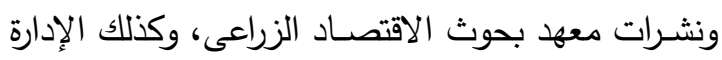

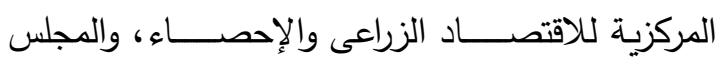

المحلى فصناعة السكر من زراعة قصب السكر تُعتبر

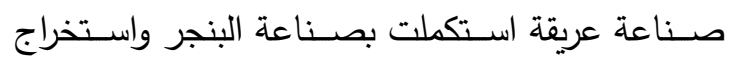

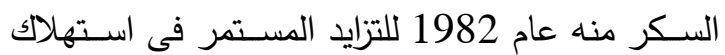
لـــــــا يُـــــعتبر الســكر من أهم الســـلع الغذائية

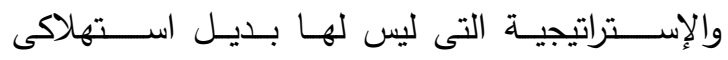

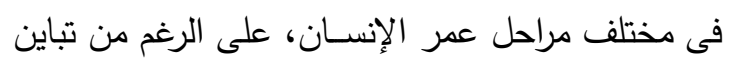
مستويات استهلاك ودخول الأفراد، إلى جانب أنى أنه يدخل الرغن

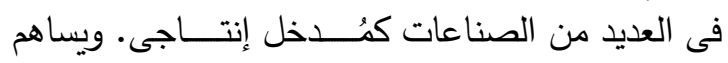

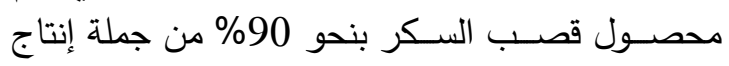
السكر فى مصر ، بالإضـافة إلى إنتاج العسل الأسـود،

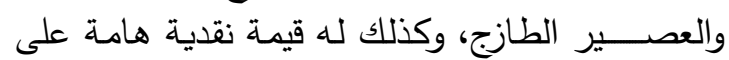

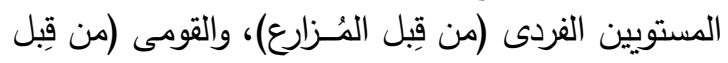
الدولة) لأنه يوفر عملات أجنبية.

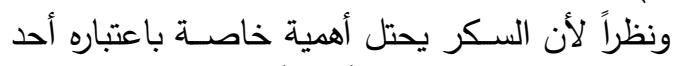

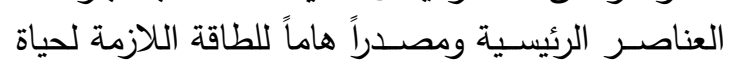

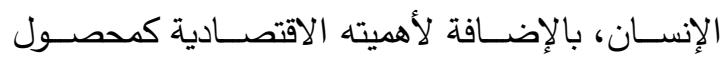

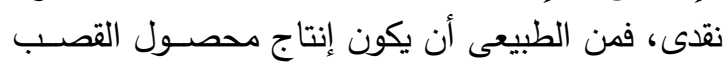

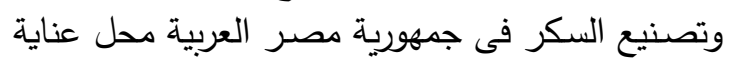
خاصة من قِبل الدولة والباحثين على حد سواء.

\section{2 المشكلة البحثية}

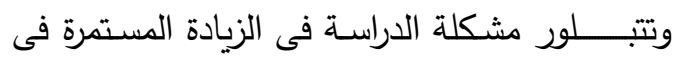

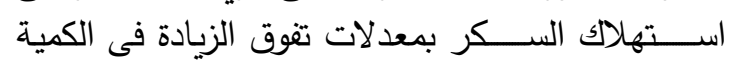

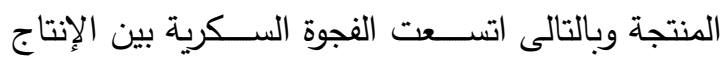

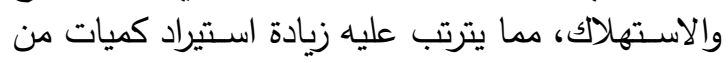

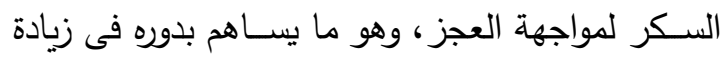

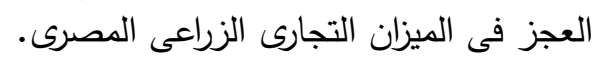

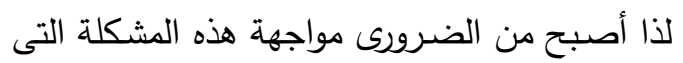

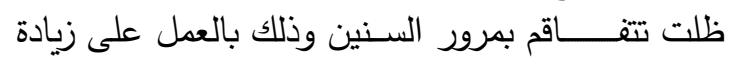

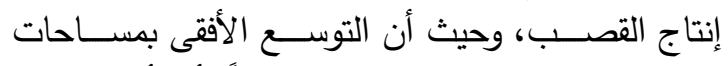

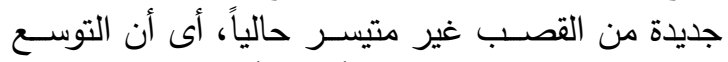

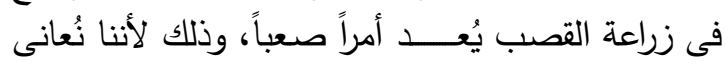
من محدودية الموارد الأرضية، وتتافس كافة المحاصيل

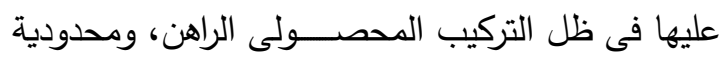

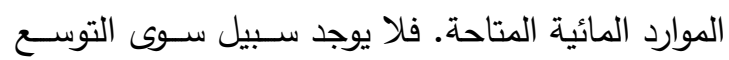

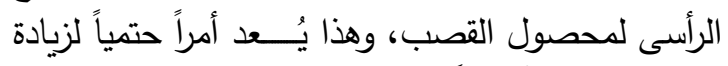

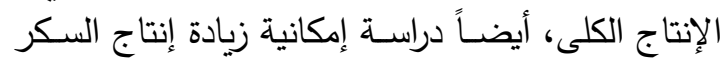


وتأسست شركة الدلتــــا لإنتاج سكر البنجـــــر عام

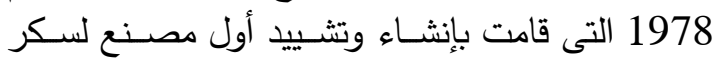

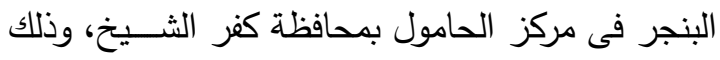

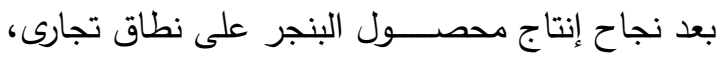

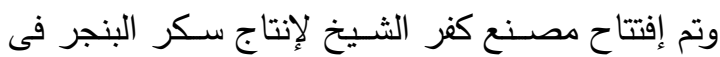
يونيه 1981 وبدأ التشغيل فى عام التشاح 1982.

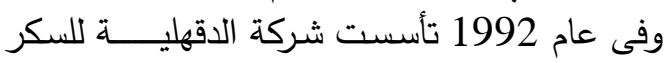

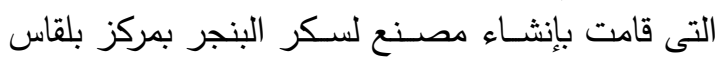

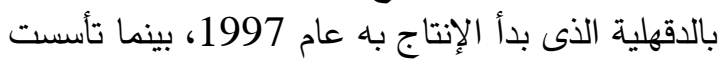

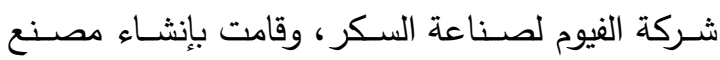

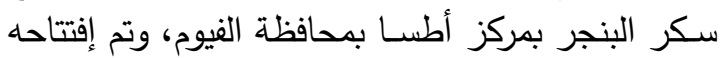
عام 2001، وقامت شركة السكر والصناعات الصنات التكاملية

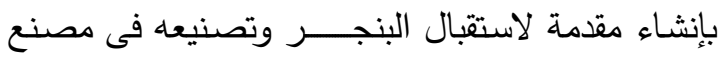
أبوقرقاص لصناعة سكر القصب بمحافظة المنيا.

3- الثركة الوطنية لمنتجات الذرة

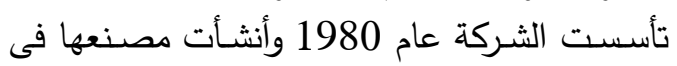

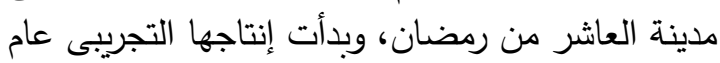

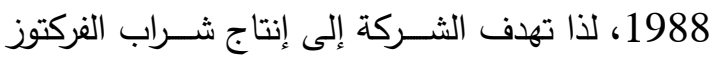

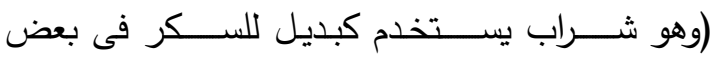

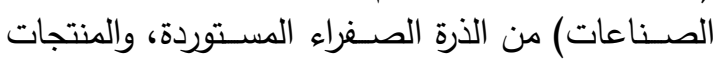

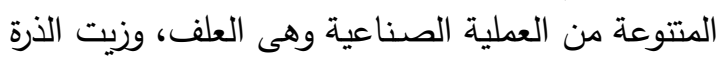

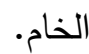

4- الثركة المصرية لصناعة النشا والجلوكوز وهى من الشركات المتخصصة فئ إنتاعة إنتاج السكريات

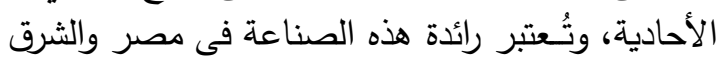

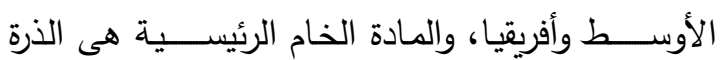

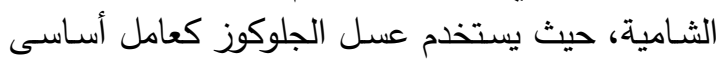

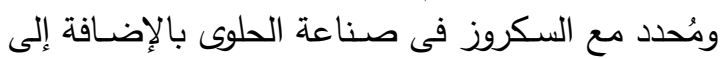

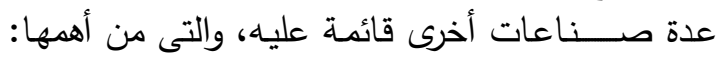

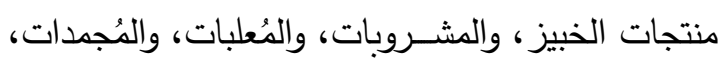

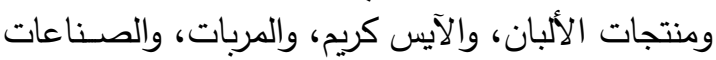
الدوائية، والصنات الأبان، والاين كريم، والكيمات

ثنانياً: العـوامل المؤثرة على محصـول قصب السكر فى مصر خـلال الفترة (2016- 2018)

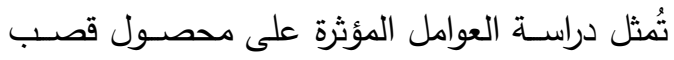

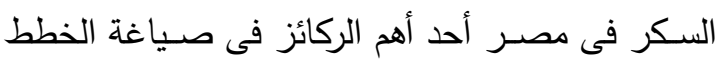

المركزى للمحاصـيل السـكرية بوزارة الزراعة، بالإضـافة

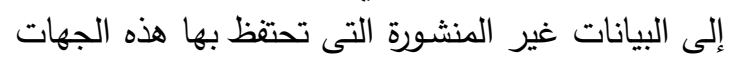
المذكورة فى سجلاتها.

أولاً: التـــــــع الجغــرافى لشركات ومصانع السكر فى تُُـــتبر شركة السكر والصناعات التكاملية من أهم شركات سكر القصب في مصر ، ويتبعها ثمانية مصانع

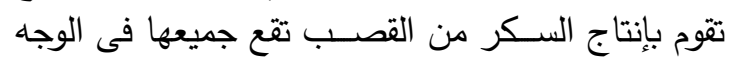

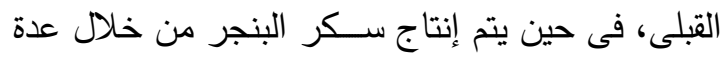

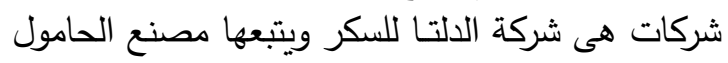

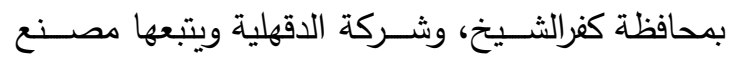

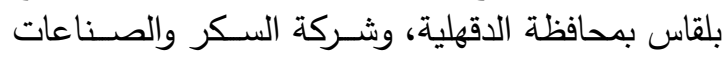

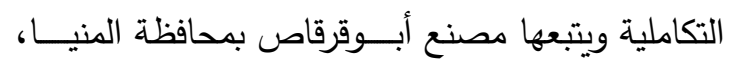

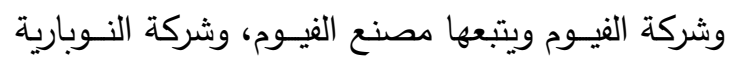
ويتبعها مصنع النوبارية بمحافظة البحيرة.

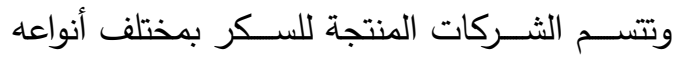

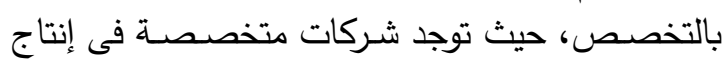

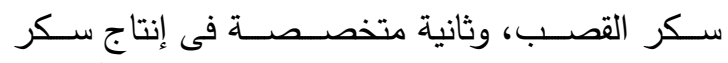
البنجر ، وثالثة متخصصة فى إنتاج السكريات الأحادية،

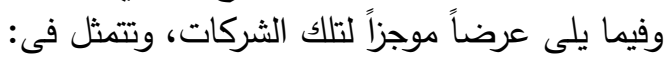

1- شركة السكر والصناعات التكاملية

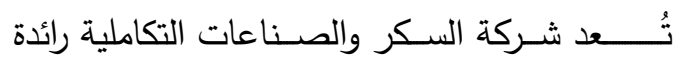

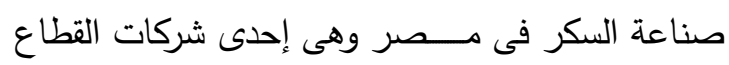

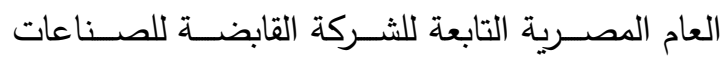

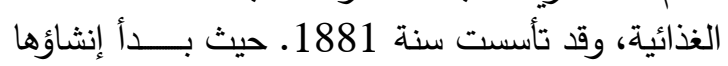

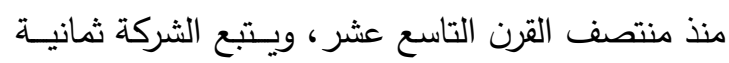

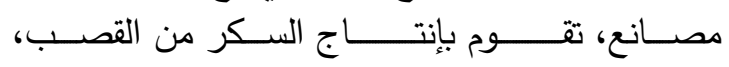
وتقع جميعها فى الوجه القبلى.

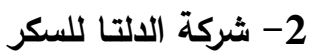

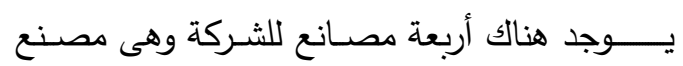

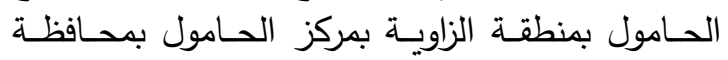

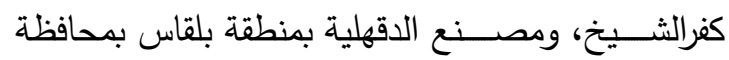

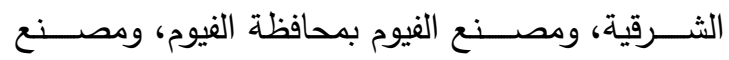

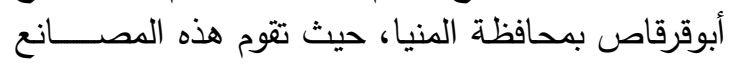
جميعها بإنتاج السكر من البنجر ل 
الجمهورية خلال الفترة (2016- 2018)، حيث بـــــن

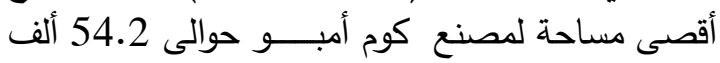
فدان كمتوسط للفترة (2016- 2018)، بينما بلغ أدنى الفى

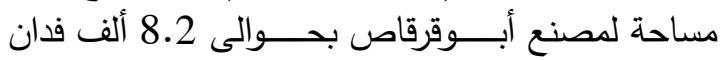
كمتوسط لنفس الفترة.

\section{4- كمية السكر المنتجة}

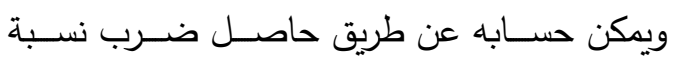

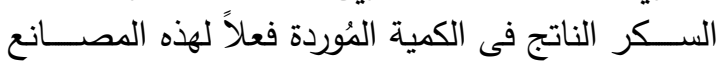

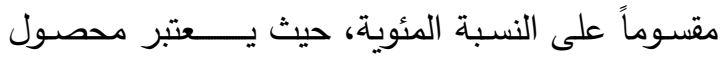

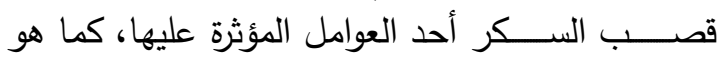

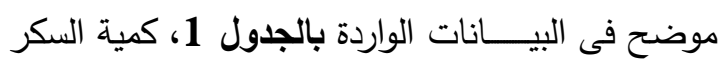

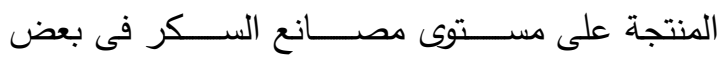

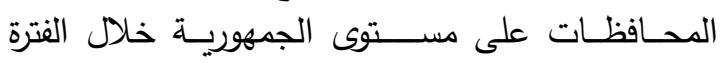

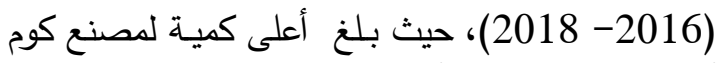

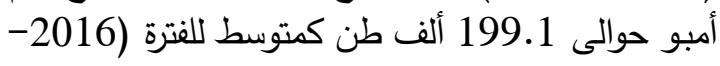

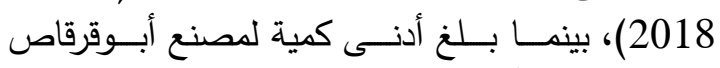
بحوالى 33.4 ألف طن كمتوسط لنفس الفترة.

\section{5- كميـة الطن المُورد}

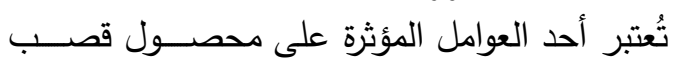

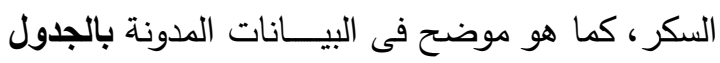

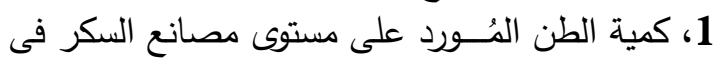

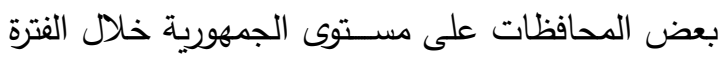

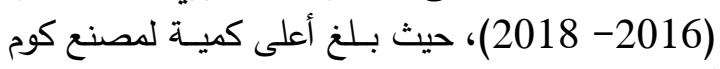

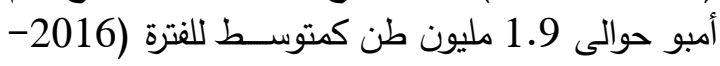

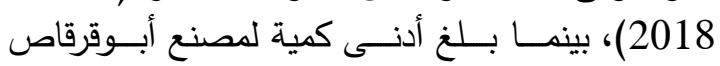
بحوالى 315.4 ألف طن كمتوسط لنفس الفترة.

\section{6- معدل توريد الفدان}

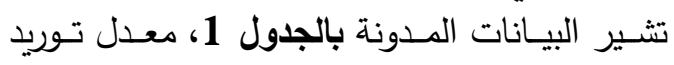

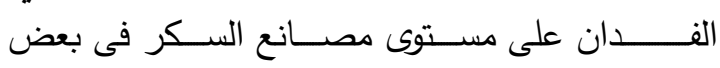

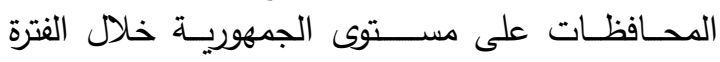

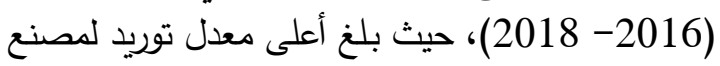

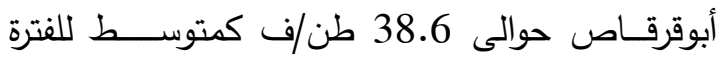

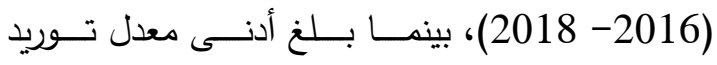

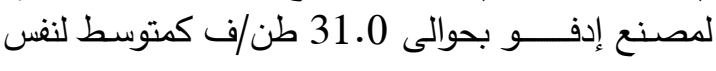

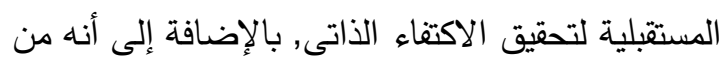

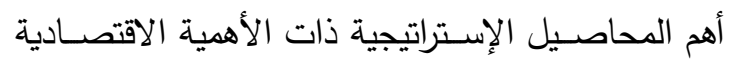

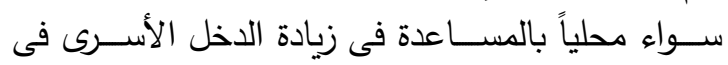

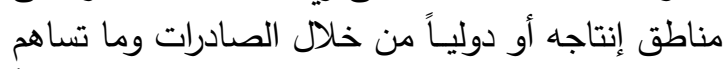

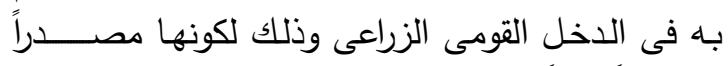

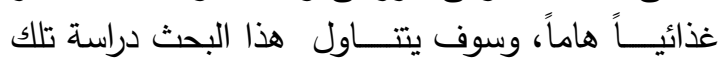

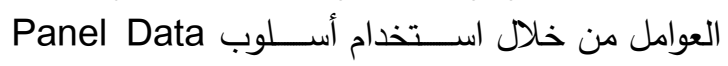

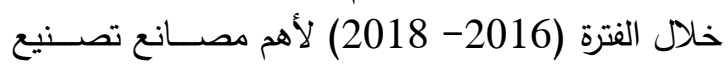
السكر فى بعض المحافظات على مستوى الجمهورية. 1- نسبة كفاءة التشغيل لعضن الفحافيل

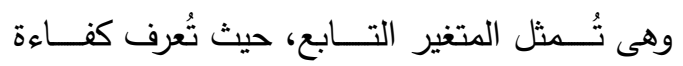

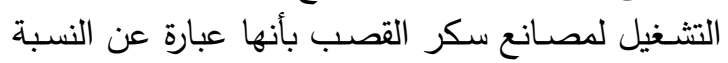

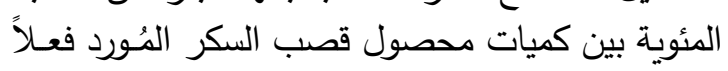

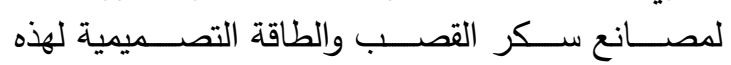

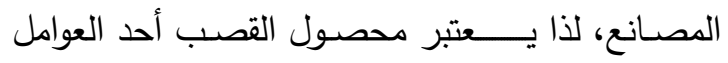

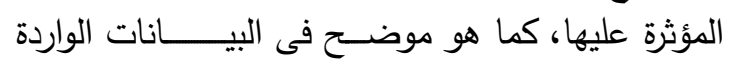

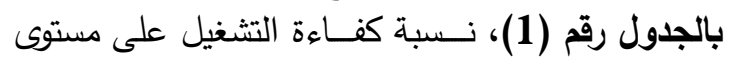

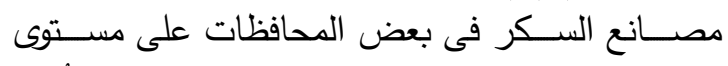
الجمهورية وذلك خلال الفترة (2016- 2018)، وتُمثل فئل

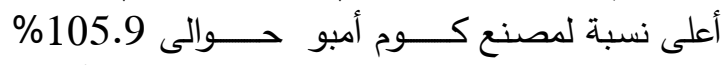

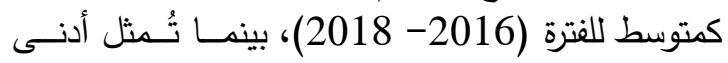

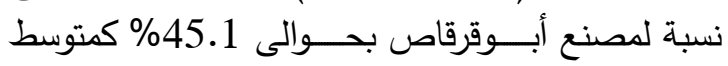

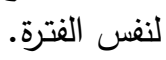

2- كمية السكر المنتجة / عدد أيام التشغيل

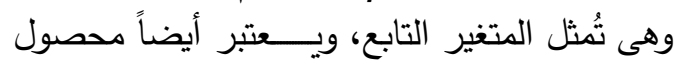

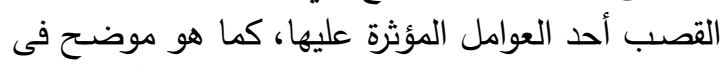
البيانات الواردة بالجدول رقم (1)، حيث بلغ أعلى كمية العبة

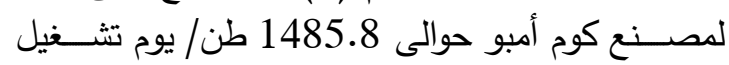

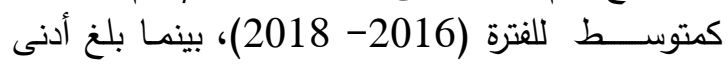

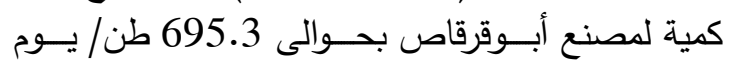
تشغيل كمتوسط لنفس الفترة.

$$
\text { 3- مساحة القصب المُوردة }
$$

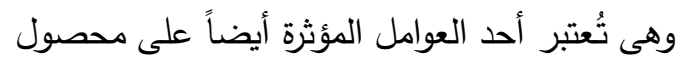

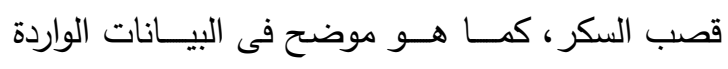

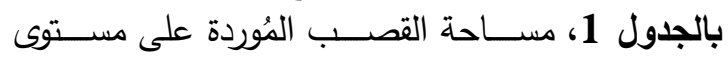

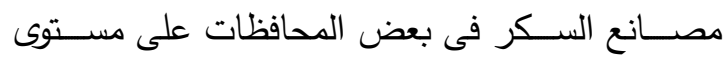


لهذه المصانع، حيث تُُـــتعبر نسبة السكر من العوامل

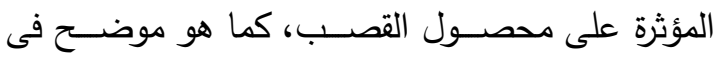

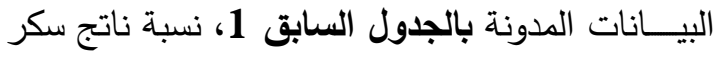

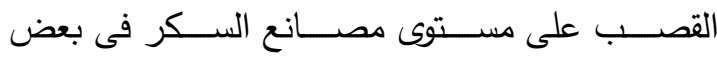

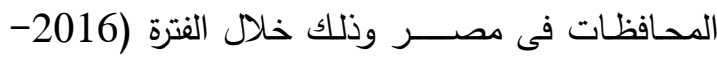

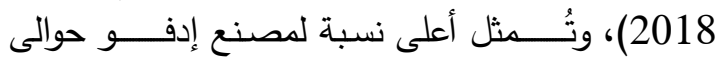

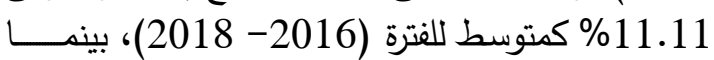

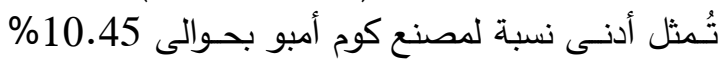
كمتوسط لنفس الفترة.

10- درجة الحلاوة ، ودرجة النقاوة

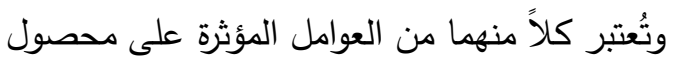

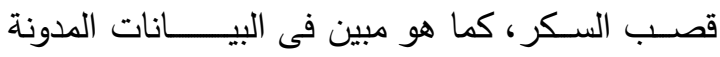

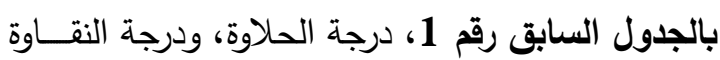

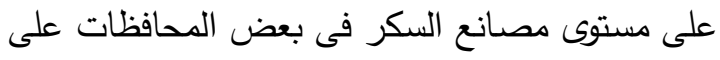

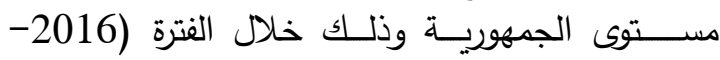

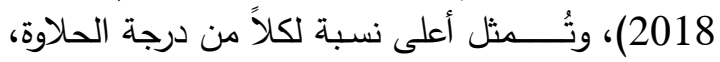

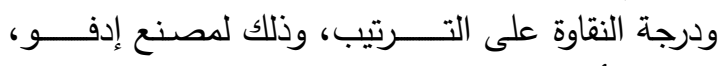

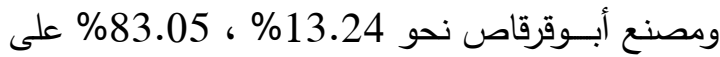
الترتيب كمتوسط للفترة (2016- 2018)، بينمـا تُمثل علئ

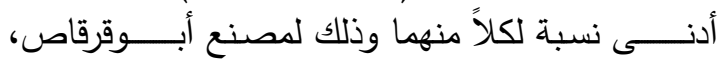

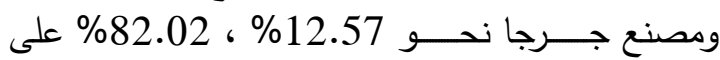
الترتيب كمتوسط لنفس الفترة.
7- كمية الطن المعصور اليومى

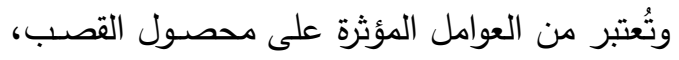

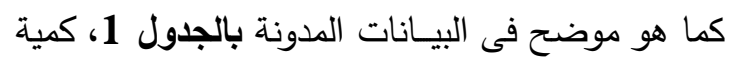

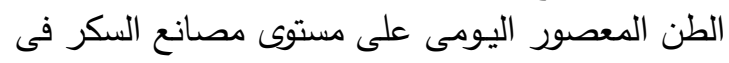

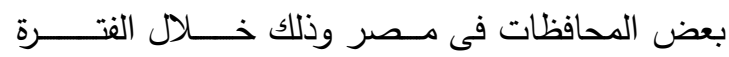

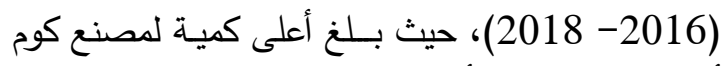
أمبو حوالى 14.3 ألــف طن كمتوسط للفترة (2016-

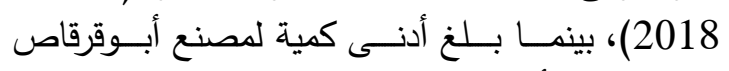
بحوالى 6.6 ألف طن كمتوسط لنفس الفترة. 8- متوسط إنتاج الفدان من السكر

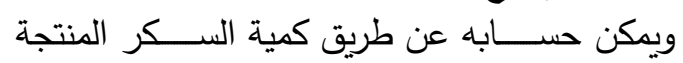

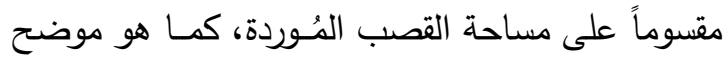

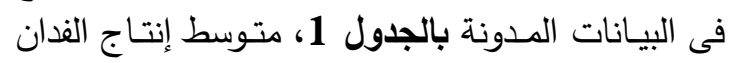

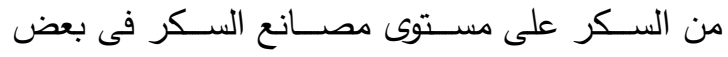

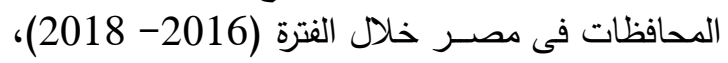

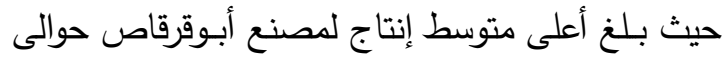

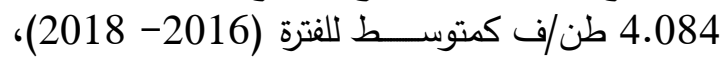

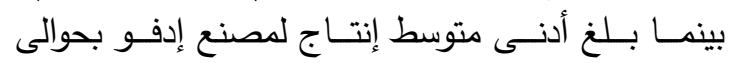
3.447 طن/ف كمتوسط لنفس الفترة.

9- 9 - 9سبة ناتج سكر القصب

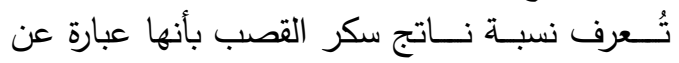
النسبة المئوية بين كمية السكر المنتجة والكمية المُوردة 


\begin{tabular}{|c|c|c|c|c|c|c|c|c|c|}
\hline$\frac{1}{e_{1}^{2}}$ & $z$ & 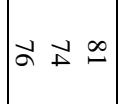 & $\bar{\omega}$ & $\vec{\partial}$ 定 & a & $N \pm \infty$ & $\stackrel{+}{\infty}$ & 士心出出 & 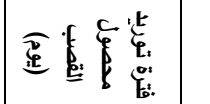 \\
\hline E; & 崩 & 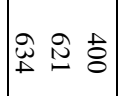 & 凶্ & 今ै & $\stackrel{\sim}{\sim}$ & 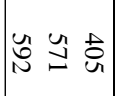 & 岁 & 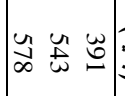 & 专 \\
\hline$\hat{E}$ & $\ddot{\infty}_{\infty}$ & $\mid \begin{array}{lll}F & \overrightarrow{0} & 0 \\
& 0 & 0 \\
\end{array}$ & 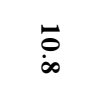 & $\mid \begin{array}{lll}\vec{i} & \vec{i} & \overrightarrow{0} \\
& 0 & 0\end{array}$ & in & 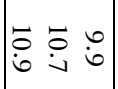 & ڤ̆ & 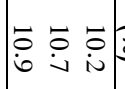 & 管 \\
\hline 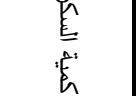 & ñ & $\left|\begin{array}{lll}N & N & N \\
\dot{u} & \dot{\omega} & \dot{b}\end{array}\right|$ & $\stackrel{n}{\omega}$ & 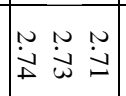 & ஸे & $\left|\begin{array}{lll}\hat{u} & N & N \\
\dot{厶} & \dot{v} & \dot{u}\end{array}\right|$ & $\dot{\vec{s}}$ & 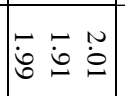 & के \\
\hline & 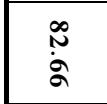 & 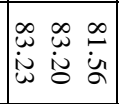 & $\stackrel{\substack{\sim \\
\omega}}{\infty}$ & 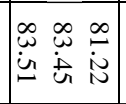 & 离 & 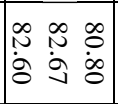 & $\begin{array}{l}\infty \\
\stackrel{\infty}{\infty} \\
\dot{\varphi} \\
u\end{array}$ & 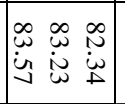 & बे \\
\hline (8) & $\begin{array}{l}\bar{\omega} \\
\dot{\varphi}\end{array}$ & 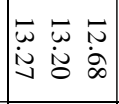 & 啇 & 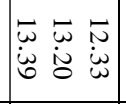 & $\begin{array}{l}\bar{N} \\
\dot{\alpha}\end{array}$ & 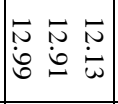 & $\begin{array}{l}\bar{i} \\
\dot{i j} \\
\end{array}$ & 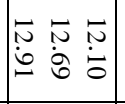 & बे \\
\hline $\bar{E}$ & $\underset{\infty}{\infty}$ & 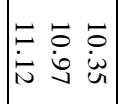 & $\underset{\dot{\phi}}{\dot{\infty}}$ & 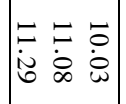 & bi & 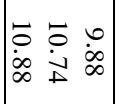 & i & 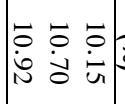 & 到 \\
\hline & $\begin{array}{l}\infty \\
\stackrel{\infty}{=}\end{array}$ & 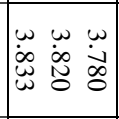 & 㝘 & 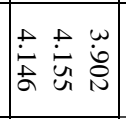 & 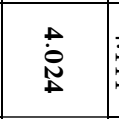 & 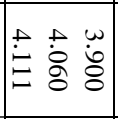 & $\begin{array}{c}\dot{p} \\
\dot{\infty} \\
\dot{\infty} \\
\dot{\infty}\end{array}$ & 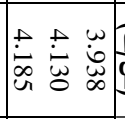 & $\frac{b_{0}}{C_{C}}$ \\
\hline & $\stackrel{\mathscr{E}}{\varrho}$ & 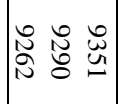 & $\underset{\infty}{\vec{\infty}}$ & 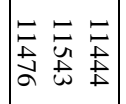 & के & 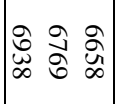 & 仓े & 空拿空 & 宦串 \\
\hline$\delta$ & $\stackrel{w}{u}$ & 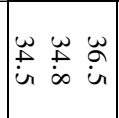 & $\stackrel{\omega}{\dot{v}}$ & 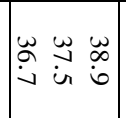 & $\begin{array}{l}\infty \\
\substack{\infty \\
i \infty} \\
\infty\end{array}$ & 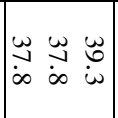 & $\begin{array}{l}\omega_{\infty} \\
\vdots \\
\sigma\end{array}$ & $\left|\begin{array}{lll}w & w & w \\
\infty & \infty & \infty \\
\dot{w} & \sigma & \infty \\
0 & \infty\end{array}\right|$ & 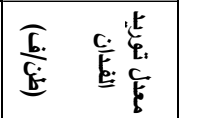 \\
\hline & 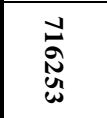 & 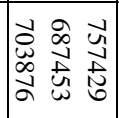 & 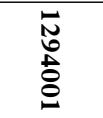 & 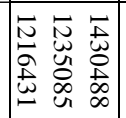 & 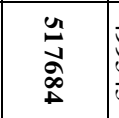 & 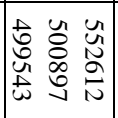 & 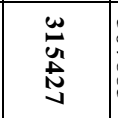 & 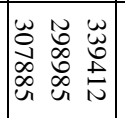 & $\widehat{E} \quad \underline{E} \underline{\underline{E}}$ \\
\hline 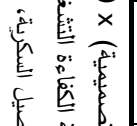 & $\underset{\omega}{\tilde{\omega}}$ & 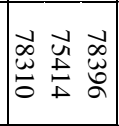 & $\begin{array}{l}\bar{E} \\
\text { W } \\
\text { N } \\
\text { N }\end{array}$ & 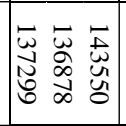 & 崩 & 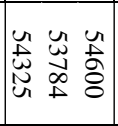 & 岕 & 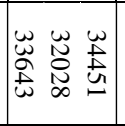 & 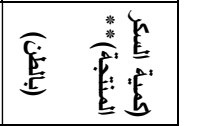 \\
\hline 是. & 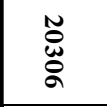 & 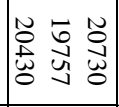 & 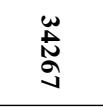 & $\mid$ & $\begin{array}{l}\bar{w}^{\prime} \\
\stackrel{\infty}{\infty}\end{array}$ & 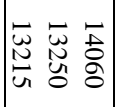 & $\stackrel{\infty}{3}$ & 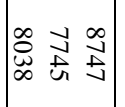 & 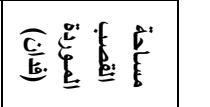 \\
\hline 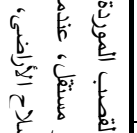 & $\underset{\substack{+\infty}}{\bar{\phi}}$ & 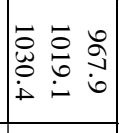 & $\underset{\substack{\tilde{N} \\
\text { N }}}{\bar{N}}$ & 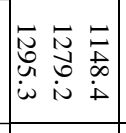 & $\begin{array}{l}\vec{y} \\
\omega \\
a\end{array}$ & 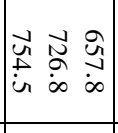 & 商 & 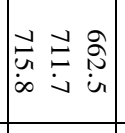 & 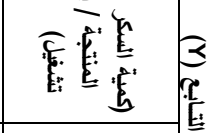 \\
\hline 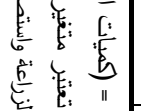 & ă & 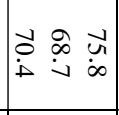 & $\stackrel{-}{-1}$ & 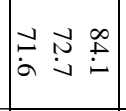 & $\stackrel{\varphi}{\infty}$ & 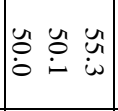 & 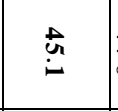 & 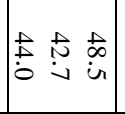 & 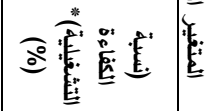 \\
\hline 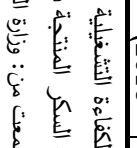 & 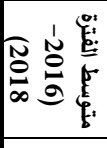 & 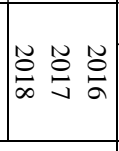 & 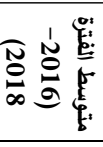 & & 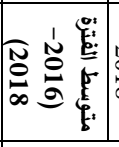 & 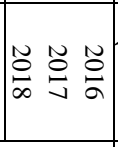 & 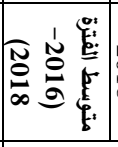 & 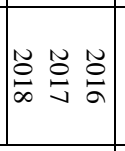 & $\hat{\varepsilon}$ \\
\hline है & \multicolumn{2}{|c|}{ مصنع دشنا } & \multicolumn{2}{|c|}{ نجع حمادى } & \multicolumn{2}{|c|}{ مصنع جرجا } & \multicolumn{2}{|c|}{ مصنع أبوقرقاص } & المصنح \\
\hline & \multicolumn{4}{|c|}{ قــنـا } & \multicolumn{2}{|c|}{ سوهاج } & \multicolumn{2}{|c|}{ المنيا } & الححافظة \\
\hline
\end{tabular}




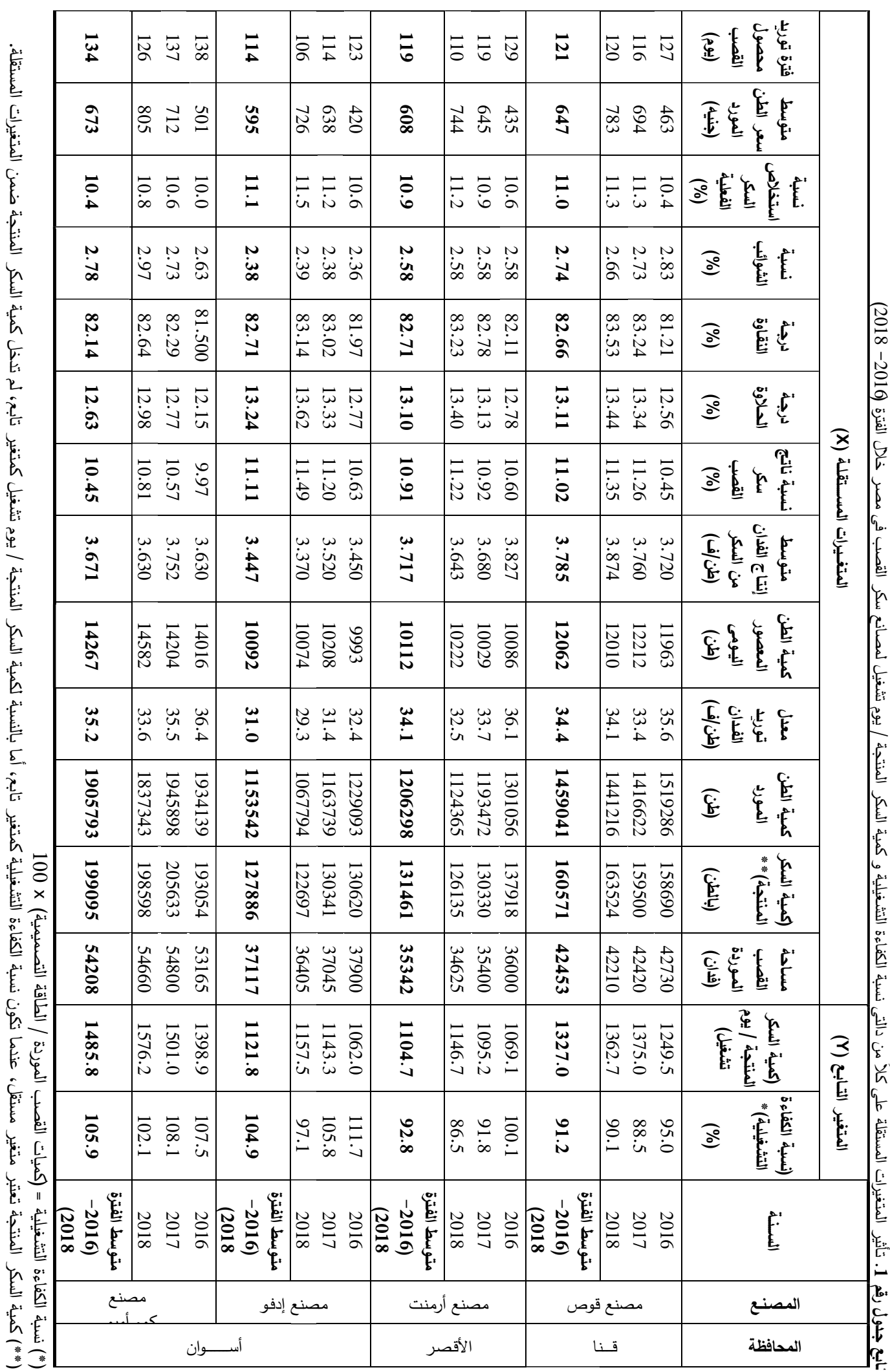




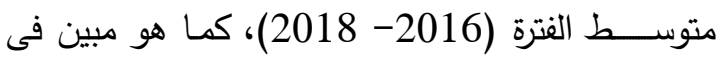

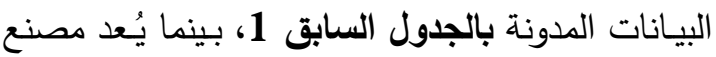

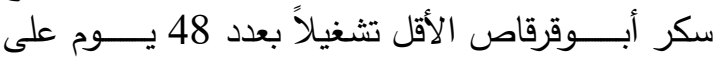
مستوى مصانع سكر القصب كمتوسط لنفس الفترة.

- تقـــــير المتفيرات المؤثرة على دالة نسبة الكفاءة

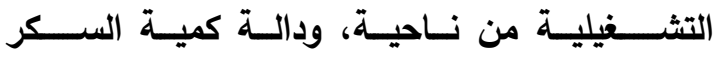

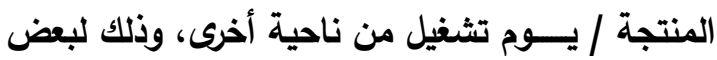

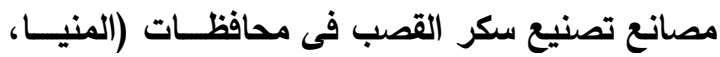

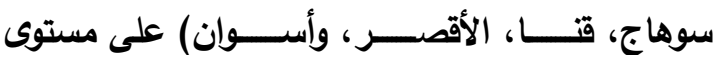
الجمهورية خلال الفترة (2016- 2018)

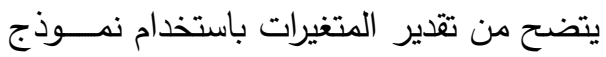

Panel Data مع عــــــد (Cross Series Data) الوحدات المقطعية (i) المتمثلة فى 8 مصــانع لتصـئيع

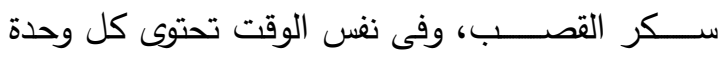

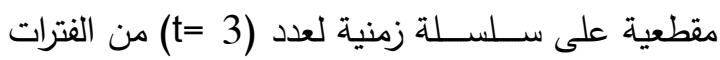

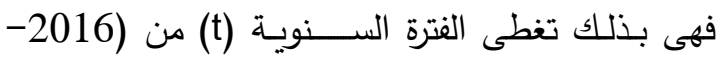

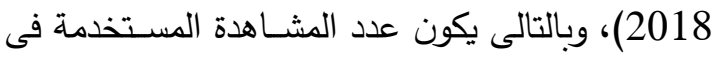
التحليل هو 72 مشاهدة.

وعلى ضــوء الدراســة المسـتخدمة فى التحليل

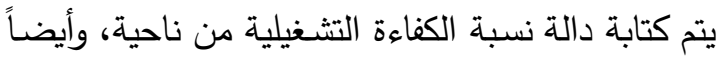

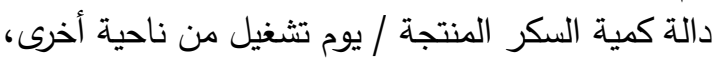
وذلك لبعض مصانع سكر القصب وفقاً للصيغة التالية:

ln $\mathrm{y}_{\mathrm{i \tau}}=\mathrm{B}_{0}+\mathrm{B}_{1} \imath n \mathrm{x}_{1 t}+\mathrm{B}_{2} \imath n \mathrm{x}_{2 t}+\mathrm{B}_{3} \imath n \mathrm{x}_{3 t}+$ $\mathrm{B}_{4} \imath n \mathrm{X}_{4 t}+\mathrm{B}_{5} \imath n \mathrm{X}_{5 t}+\mathrm{B}_{6} \imath n \mathrm{X}_{6 t}+$

$\mathrm{B}_{7} \imath n \mathrm{X}_{7 t}+\mathrm{B}_{8} \imath n \mathrm{X}_{8 t}+\mathrm{B}_{9} \imath n \mathrm{X}_{9 t}+\mathrm{B}_{10} \imath n \mathrm{X}_{10 t}+$ $\mathrm{B}_{11} \ln \mathrm{x}_{11 t}+\mathrm{D}$

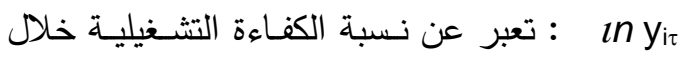
الفترة (2016- 2018)، وهو يمثل المتغير التابع. In yi

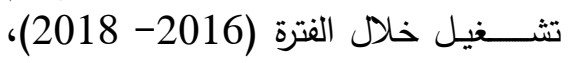

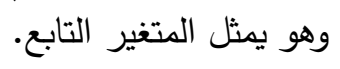

11 - نسبة الثوائب

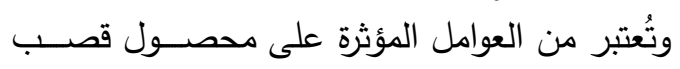

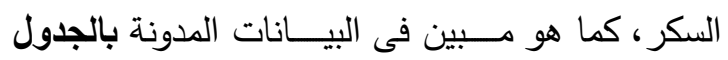

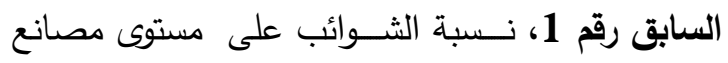

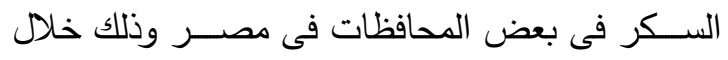

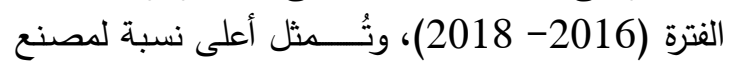

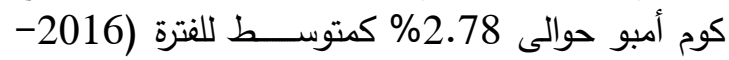

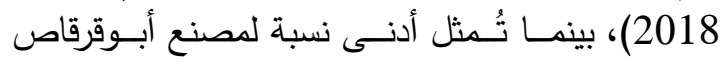
بحوالى 1.97\% كمتوسط لنفس الفترة.

12- نسبة استخلاص السكر الفعلية

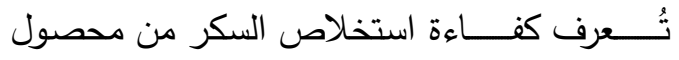
القصب بأنها عبارة عن النسبة المئوية بين كميات سكر العرك

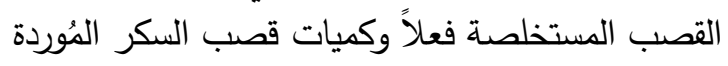

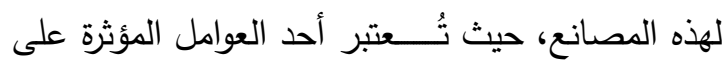

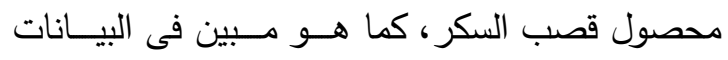

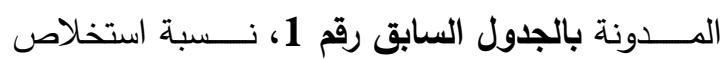

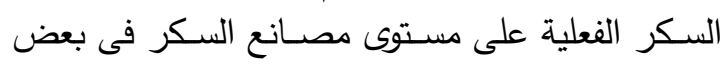

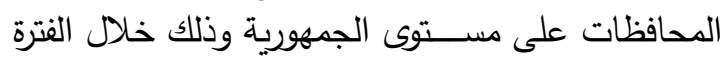

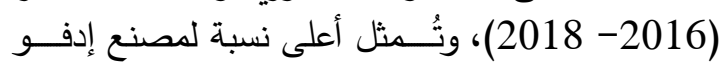

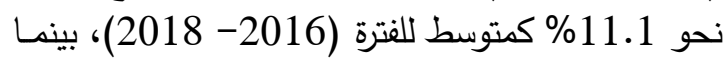

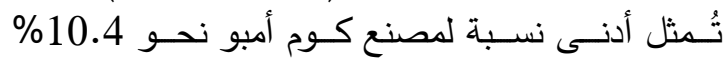
كمتوسط لنفس الفترة.

13- متوسط سعر الطن المُورد

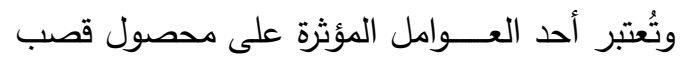

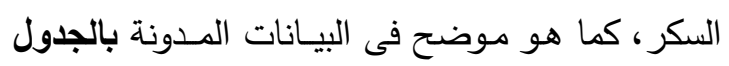

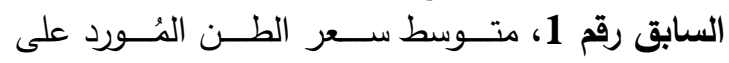

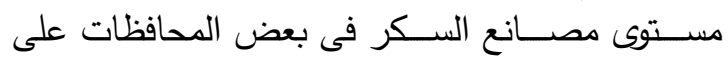

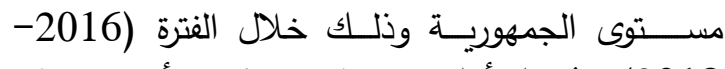

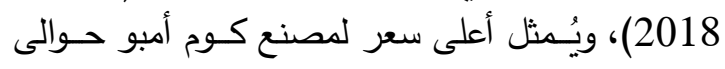

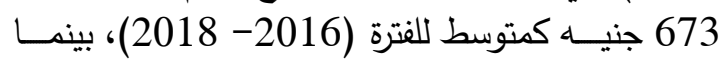

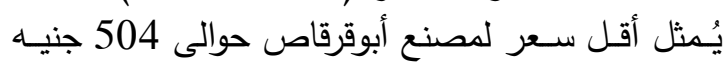
كمتوسط لنفس الفترة.

14- فترة التوريــ اليومى لمحصول القصب

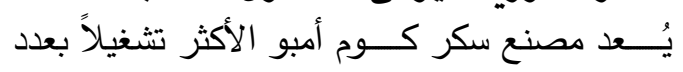
134 يــــوم على مستوى مصـانع سكر القصب خدي خلال 
حيث شــلت الدراســة 8 مصــانع لتصـنيع سـكر

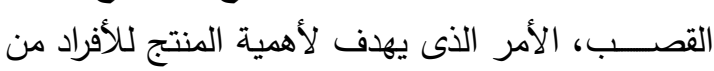
حيث الاستهلاك وزيادة الاذل الأسرى للأفراد.

1- تقدير معادلة نسبة الكفاءة التشغيلية

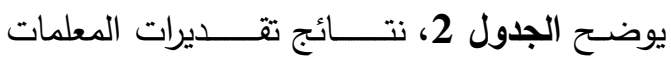

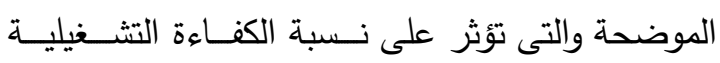

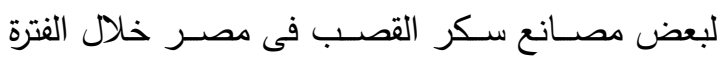

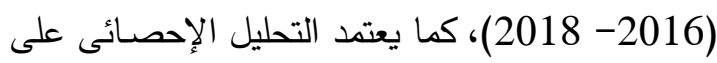

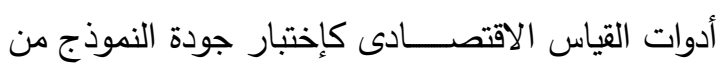

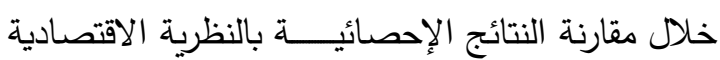
والتأكد إن كانت توافقها أو تتناقض معها.

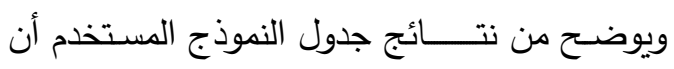
متغير ln $x_{1 t}$

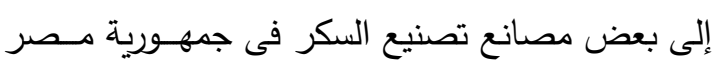

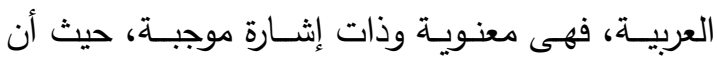

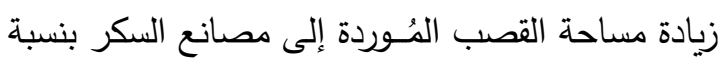

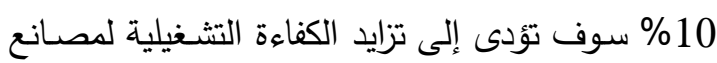

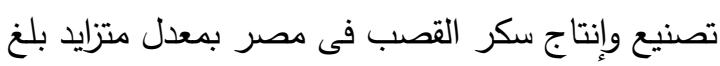
نحو 58.9\%، الأمر لذى يهدف إلى زيادة كمية السكر بـان

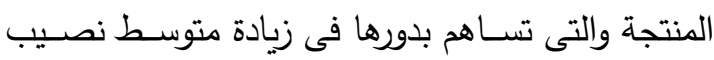
الفرد منها، وهذا يتوافق مع النظرية الاقتصادية.

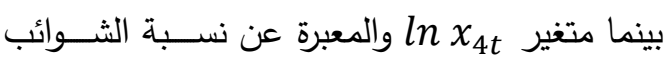

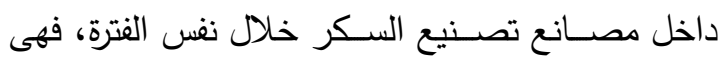
معنوية وذات إثارة سالبة، حيث أن زيادة نسبة الثوائب

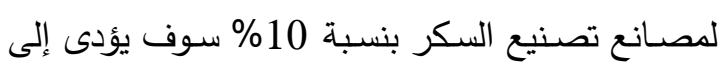

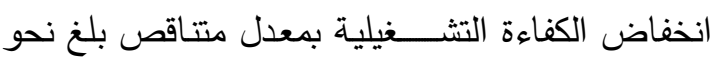

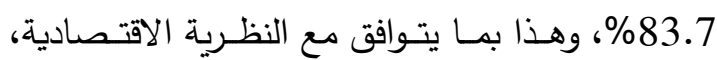

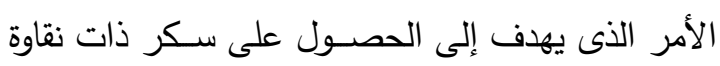

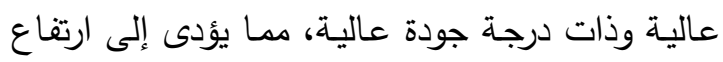
سكر التصب، كما يؤدى إلى زيادة الطلب عليه.

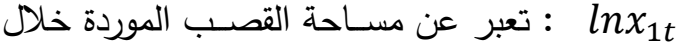
الفترة (2016- 2018).

: تعبر عن كمية الســكر المنتجـة خلال الفترة (2016- 2018).

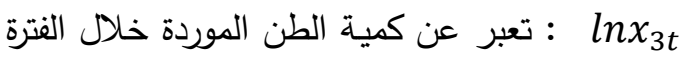
(2018 -2016)

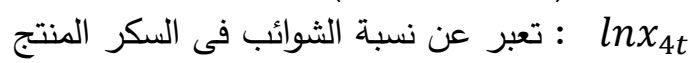
خلال الفترة (2016- 2018 2018).

: تعبر عن معدل توريد الفدان خلال الفترة (2016)

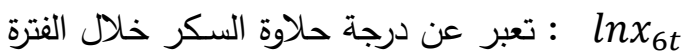
(2018 - 2016)

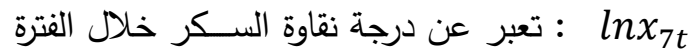
(2018 -2016)

المبر : العبر عن كمية القصب المعصورة خلال

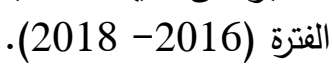

: تعبر عن نسبة استخلاص السكر الفعلى

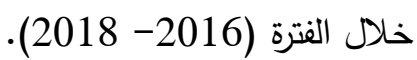

: lnx $10 t$

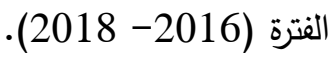

: العبر عن نسبة ناتج سكر القصب خلال $\ln x_{11 t}$ الفترة (2016- 2018).

: يعبر عن المتغير الضمنى لمصنع سكر : D أبوقرقاص.

: يعبر عن المتغير الضمنى لمصنع سكر : D جرجا.

: يعبر عن المتغير الضمنى لمصنع سكر : D

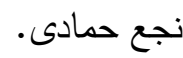

يعبر عن المتغير الضمنى لمصنع سكر : D D دشنا.

: يعبر عن المتغير الضمنى لمصنع سكر : D قوص.

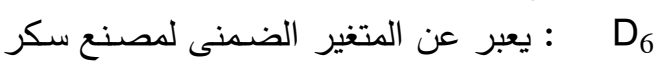
إدفو • بعن عن

: يعبر عن المتغير الضمنى لمصنع سكر : D

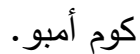


ويتبين من النتائج أن متغير ln $x_{10 t}$

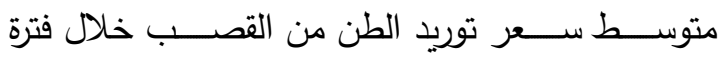
الدراسة، فهى معنوية وذات إثارة سالبة، حيث أن زيادة

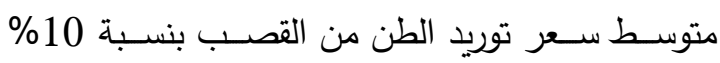

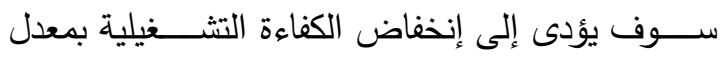

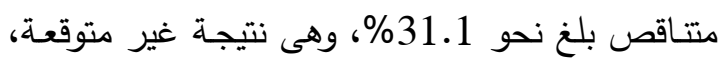

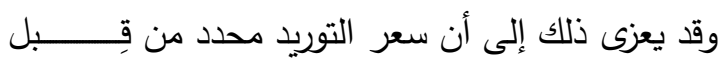
الحكومة، ولا يتغير كثيراً من مصنع إلى آخر . لتوند

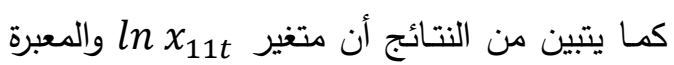
عن نسبة ناتج سكر القصب خلائ فئل فترة الدراسـة، فهى غير معنوية، وذات إثارة سالبة.

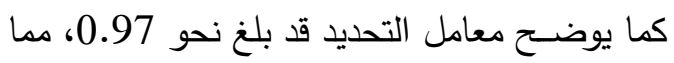

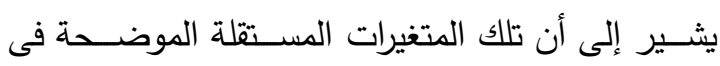

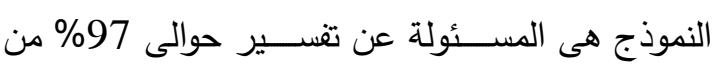

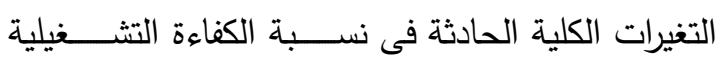
لبعض مصـانع إنتاج وتصنيع السكر فى مصر خلاد فلئل فترة الدراسة.

2- تقــــير معــــادلة نسبة الكفاءة التشغيلية بوجود

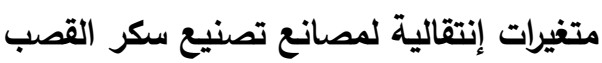

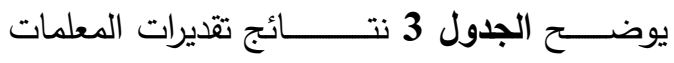

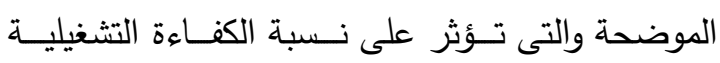

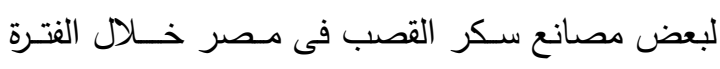

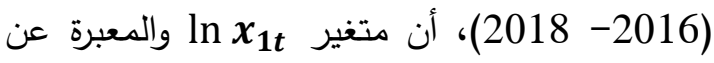

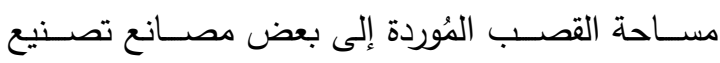

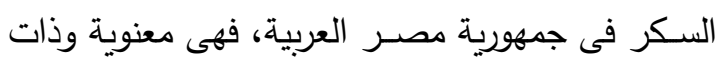

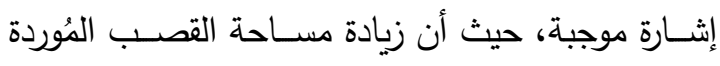
إلى مصانع السكر بنسبة 10\% سوف تئدى إلى تزايد

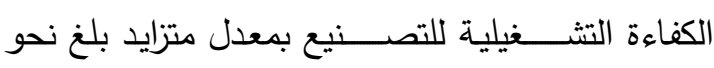

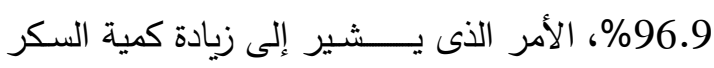

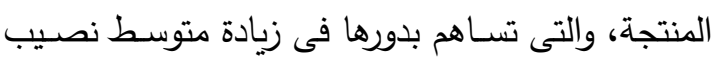
الفرد منها، وهذا يتوافق مع النظرية الاقتصادية.
جدول 2. نتائج النموذج المستخدم

\begin{tabular}{|c|c|c|}
\hline Variable & Coefficient & t- statistic \\
\hline Constant & -4.73 & $(-2.90)^{* *}$ \\
\hline $\ln x_{1 t}$ & 0.589 & $(21.08)^{\star *}$ \\
\hline $\ln x_{4 t}$ & -0.837 & $(-4.49)^{\star *}$ \\
\hline $\ln x_{6 t}$ & 5.23 & $(2.31)^{\star \star}$ \\
\hline $\ln x_{10 t}$ & -0.311 & $(-3.20)^{\star *}$ \\
\hline $\ln x_{11 t}$ & -3.18 & $(-1.67)$ \\
\hline R-squared & \multicolumn{2}{|c|}{0.974} \\
\hline $\begin{array}{l}\text { Adjust R- } \\
\text { squared }\end{array}$ & \multicolumn{2}{|c|}{0.967} \\
\hline F- statistic & \multicolumn{2}{|c|}{138.12} \\
\hline $\begin{array}{c}\text { Akaike info } \\
\text { criterion }\end{array}$ & \multicolumn{2}{|c|}{-2.73} \\
\hline Log likelihood & \multicolumn{2}{|c|}{38.73} \\
\hline
\end{tabular}

ويتبين من النتائج أن متغير

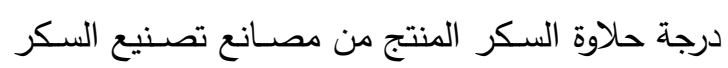

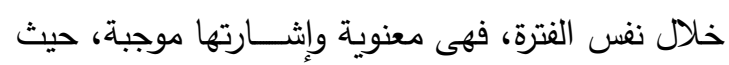

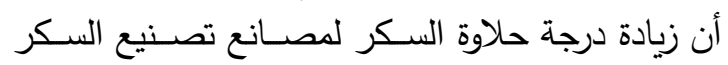
بنسـبة 10\% ســوف يؤدى إلى تزايد الكفاءة التشـغيلية

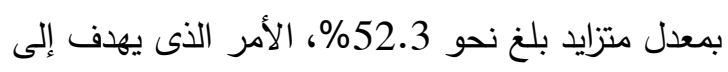

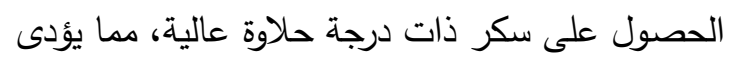

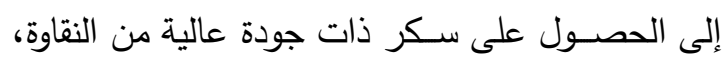

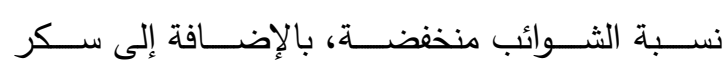

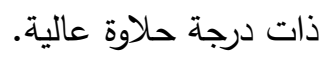


ويتبين من النتائج أن متغير ln $x_{10 t}$

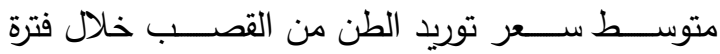

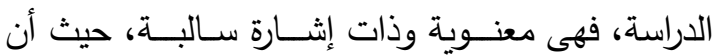
زيادة متوســ ســعر توريد الطن من القصــبـ بنســبة 10\% سوف تؤدى إلى إنخفاض نسبة الكفاءة التشغيلية بمعدل متتاقص بلغ نحو 18.1\% كما يتبين من النتائج أن متغير

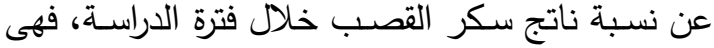
غير معنوية وذات إثارة سالبة.

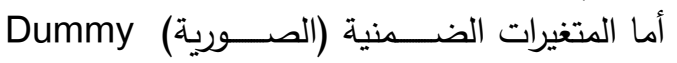
Variables Qualitative Variables معينـة مثل (اللون، الديانـة، الجنس أو النوع، الحرب

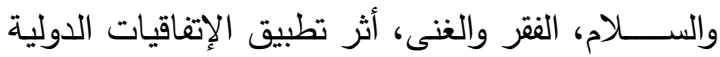

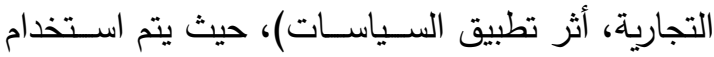
القيمة واحد صحيح (1) للالالة على وجود صفة معينة،

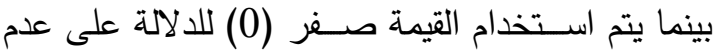
وجود صــــة معينة، لذا يمكن أن تكون هذه المتغيرات

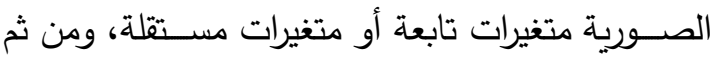
فإن المتغيرات التى تأخذ قيمها (0 ، 1 1) تعتبر متغيرات

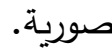
وأوضحت النتائج أن مصنـع أبـــــوقرقاص بمحافظة

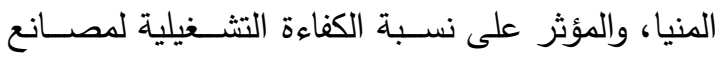
تصنيع سكر القصب بمعدل متزايد بلغ نحو 85.1\% بينما مصنع دشنا بمحافظة قنـــــا، والمؤثر على نسبة الفية

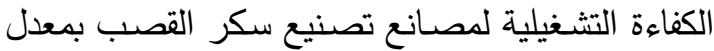
متزايد بلغ نحو 49.1\%، أما مصنعى (إدفــــــو، وكوم إمبو) بمحافظة أسـوان، والمؤثرين في الكفاءة التثــئلية

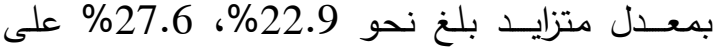

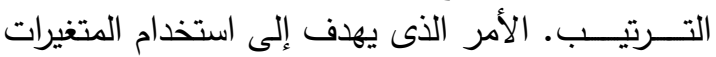
الضمنية هو تقسير أثر صفة معينة على متغير معين مثل قياس أثر تطبيق إتفاقية الجات قبل وبعد تطبيقها

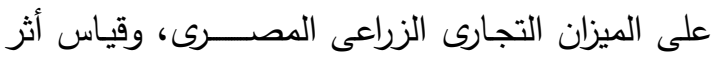

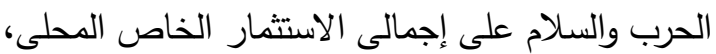

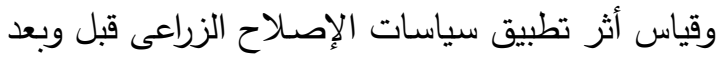

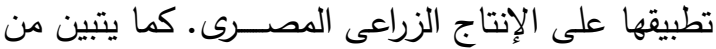

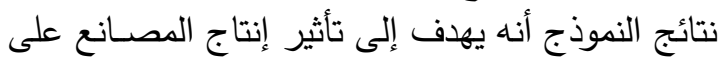
نسبة الكفاءة التشغيلية لمصانع تصنيع سكر القصب.
جدول 3. نتائج النموذج المستخدم

\begin{tabular}{|c|c|c|}
\hline Variable & Coefficient & t- statistic \\
\hline Constant & -5.62 & $(-1.998)$ \\
\hline $\ln x_{1 t}$ & 0.67 & $(4.62)^{* * *}$ \\
\hline $\ln x_{4 t}$ & -0.23 & $(-1.21)$ \\
\hline $\ln x_{6 t}$ & 0.46 & $(0.30)$ \\
\hline $\ln x_{10 t}$ & -0.18 & $(-2.48)^{* * *}$ \\
\hline $\ln x_{11 t}$ & -0.02 & $(-0.02)$ \\
\hline $\mathrm{D}_{1}$ & 0.85 & $(2.36)^{*}$ \\
\hline $\mathrm{D}_{2}$ & 0.57 & $(2.01)$ \\
\hline $\mathrm{D}_{3}$ & 0.09 & $(0.94)$ \\
\hline $\mathrm{D}_{4}$ & 0.49 & $(2.50)^{* * *}$ \\
\hline $\mathrm{D}_{5}$ & 0.06 & $(1.23)$ \\
\hline $\mathrm{D}_{6}$ & 0.23 & $(2.79)^{* * *}$ \\
\hline $\mathrm{D}_{7}$ & 0.28 & $(4.05)^{* * *}$ \\
\hline $\mathrm{R}$ - squared & \multicolumn{2}{|c|}{0.998} \\
\hline $\begin{array}{c}\text { Adjust R- } \\
\text { squared }\end{array}$ & \multicolumn{2}{|c|}{0.996} \\
\hline F- statistic & \multicolumn{2}{|c|}{561.37} \\
\hline $\begin{array}{c}\text { Akaike info } \\
\text { criterion }\end{array}$ & \multicolumn{2}{|c|}{-4.89} \\
\hline Log likelihood & \multicolumn{2}{|c|}{71.69} \\
\hline
\end{tabular}

Eviews المصدر: نتــائج التحليـلـل من خلال بـرنـامج .Ver"10"

بينما متغير ln $x_{4 t}$ والمعبرة عن نســبة الثــوائب داخل مصانع تصنيع السكر خلال الفترة، فهى غير معنوية وذات إثـارة سالبة. ويتبين من النتائج أن متغير النيا

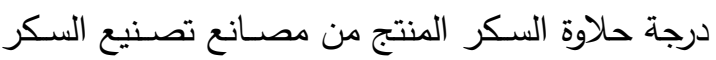
خلال نــفس الفــترة، فهى غير معنـوية وذات إثـــارة

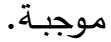


مساحة القصب المُوردة إلى مصانع سكر القصب بنسبة

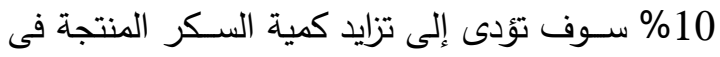

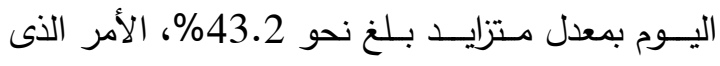

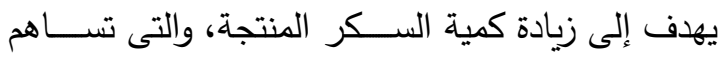

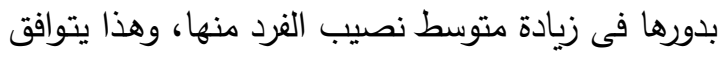
مع النظرية الاقتصادية.

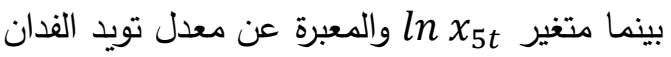

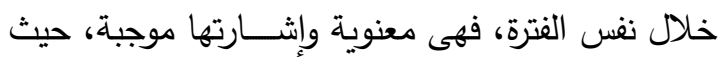

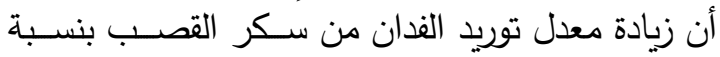

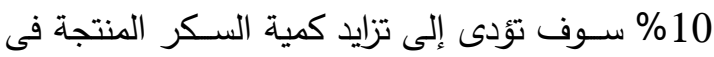

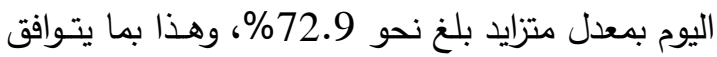

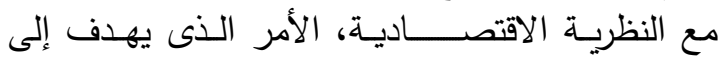

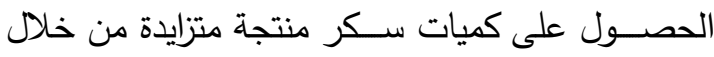
التوريد المتزايد فى عملية التصنيع.

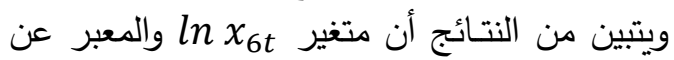

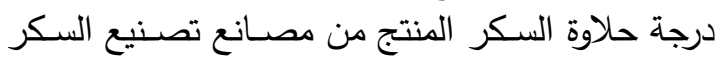

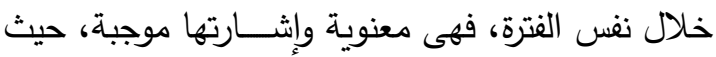

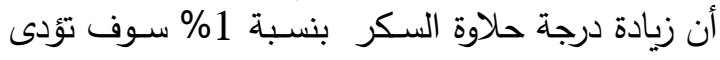

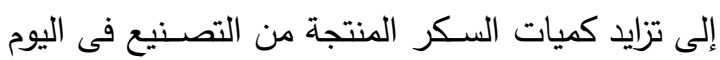

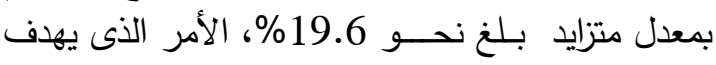

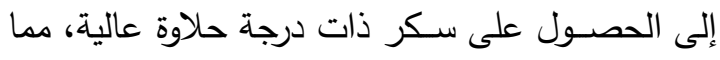

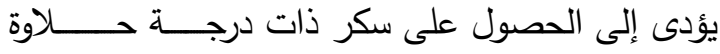
عاليـة.

كما يوضح معامل التحديد فقد بلغ نحو 0.92، مما

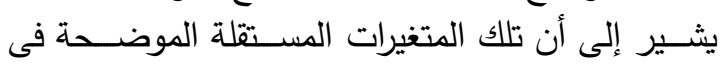

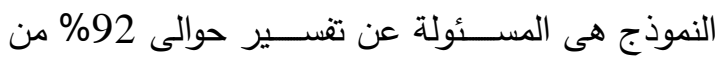

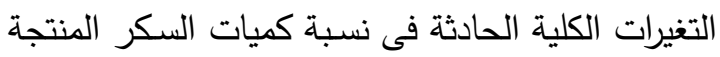

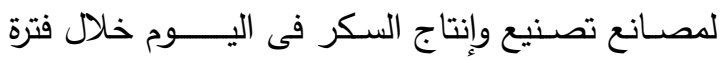

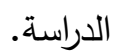

4- تقــــــر معـادلة كميـة السكر المـنتجـة فى اليـوم

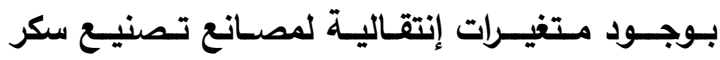

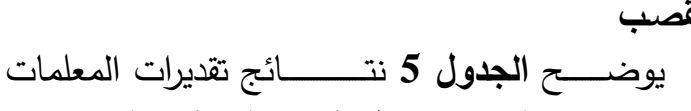

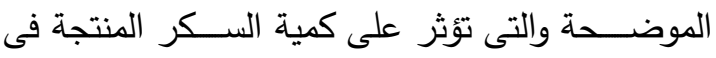

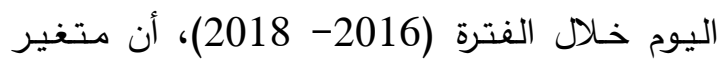

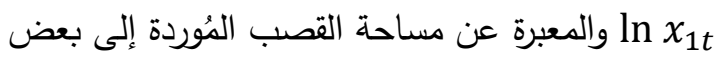

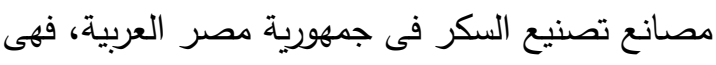
غير معنوية وذات إشـارة موجبـة.
كما يوضــح معامل التحديد فقد بلغ نحو 0.998 ،

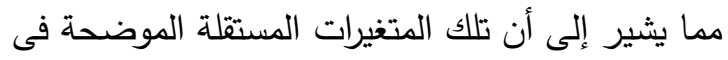

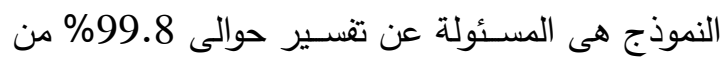

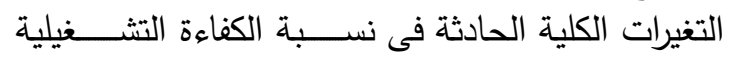

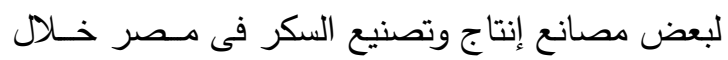

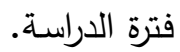

3- تقدير معادلة كمية السكر المنتجة على عدد أيـام التشغيل

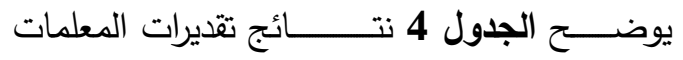
الموضحة والتى تؤثر على كمية السكر على عدد أيسام

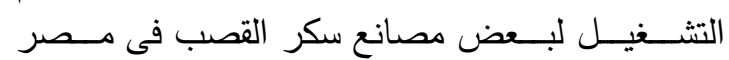

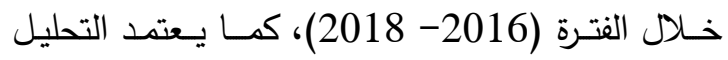

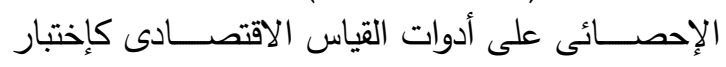

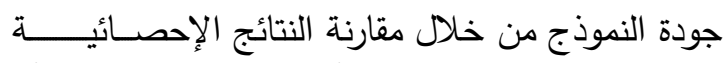

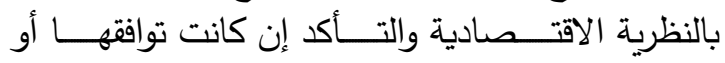

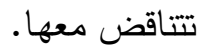
جدول 4. نتائج النموذج المستخدم

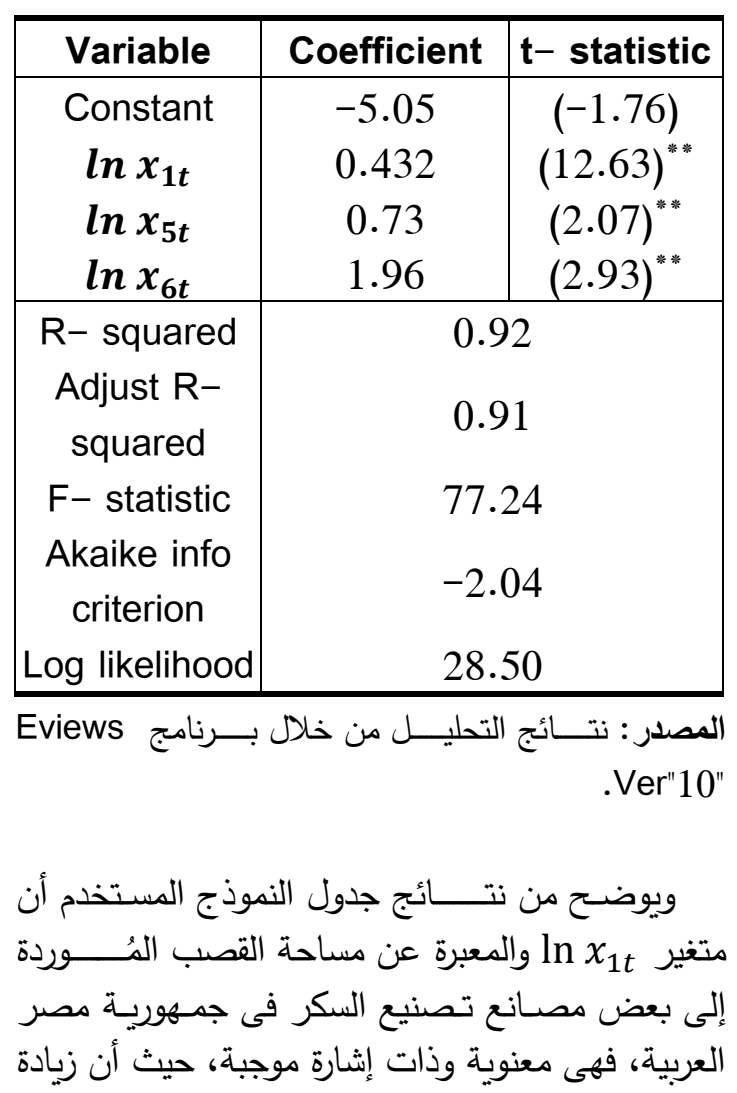




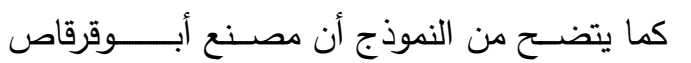

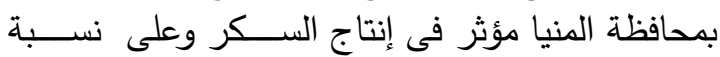

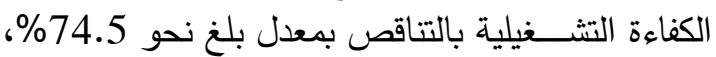

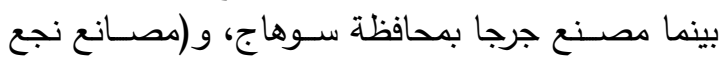

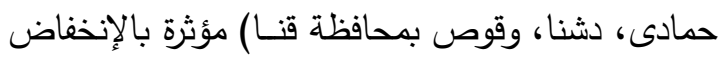

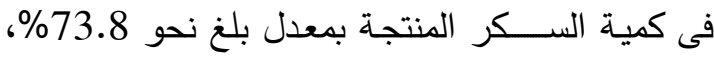

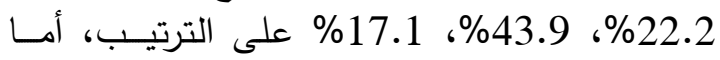
(مصـانع إدفو، وكوم إمبو) بمحافظة أسـوان، والمؤثرين

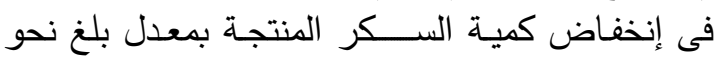

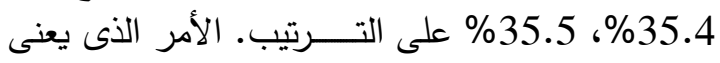

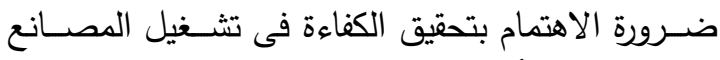

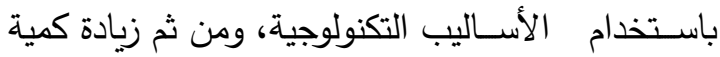

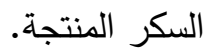

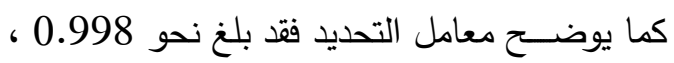

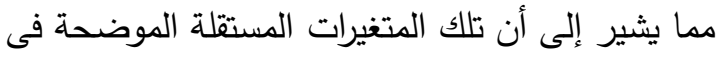

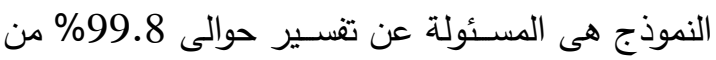

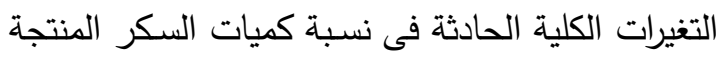

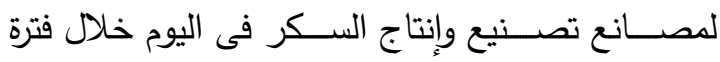

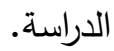

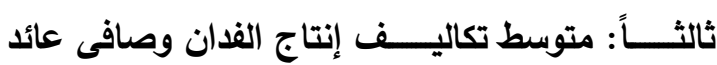

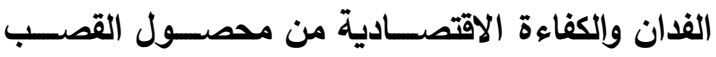
بجمهوريسة مصــر العربيـة خلال الفترة (2013(2018

1-متوسـط تكاليف إنتاج الفدان من محصـول قصب

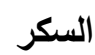
تــشير بيــانات الجدول 6، متوسط تكاليف إنتاج

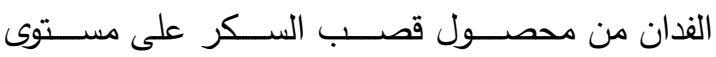

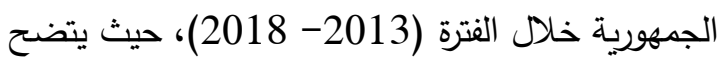

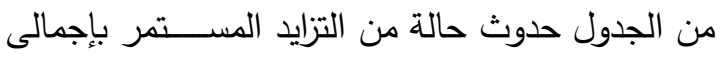

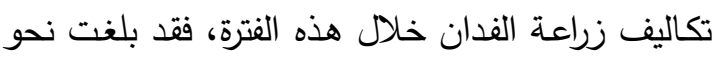

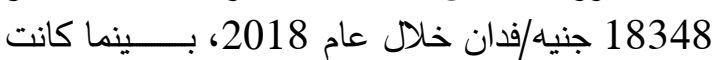

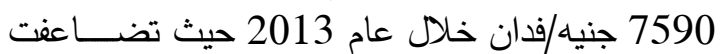
خلال هذه الفترة. كما يوضـح الجدول أيضـاً التزايد المستمر بالإيجار

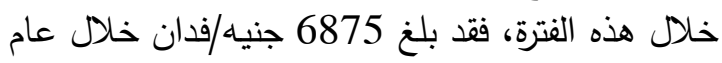

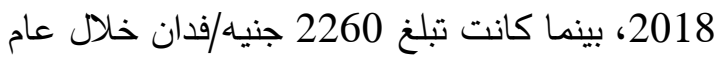

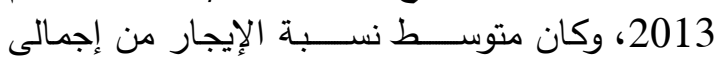
التكاليف خلال هذه الفترة حوالى 29.8\%
بينما متغير ln $x_{5 t}$

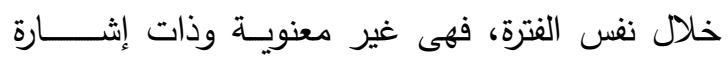

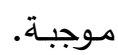

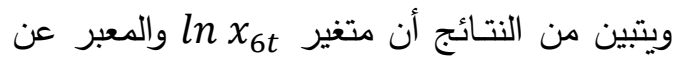

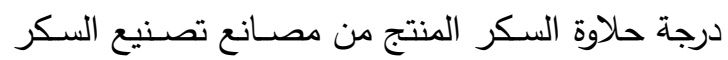

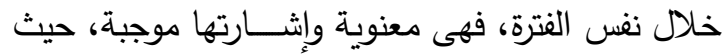

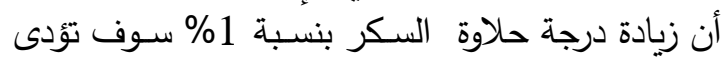

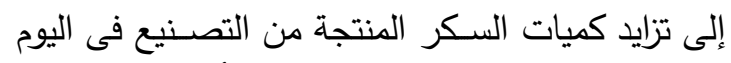

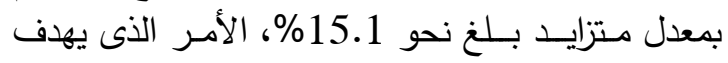

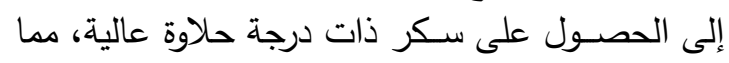

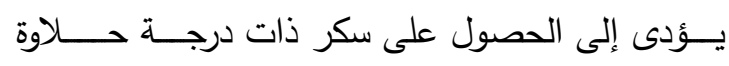

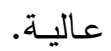
جدول 5. نتائج النموذج المستخدم

\begin{tabular}{|c|c|c|}
\hline Variable & Coefficient & t- statistic \\
\hline Constant & 3.42 & $(1.66)$ \\
\hline $\ln x_{1 t}$ & 0.004 & $(0.03)$ \\
\hline $\ln x_{5 t}$ & 0.002 & $(0.01)$ \\
\hline $\ln x_{6 t}$ & 1.51 & $(7.26)^{* * *}$ \\
\hline $\mathrm{D}_{1}$ & -0.745 & $(-3.25)^{* * *}$ \\
\hline $\mathrm{D}_{2}$ & -0.738 & $(-4.43)^{* * *}$ \\
\hline $\mathrm{D}_{3}$ & -0.222 & $(-4.24)^{* * *}$ \\
\hline $\mathrm{D}_{4}$ & -0.439 & $(-3.77)^{* * *}$ \\
\hline $\mathrm{D}_{5}$ & -0.171 & $(-6.06)^{* * *}$ \\
\hline $\mathrm{D}_{6}$ & -0.354 & $(-7.06)^{* * *}$ \\
\hline $\mathrm{D}_{7}$ & -0.355 & $(-7.22)^{* * *}$ \\
\hline$R$ - squared & \multicolumn{2}{|c|}{0.998} \\
\hline $\begin{array}{c}\text { Adjust R- } \\
\text { squared }\end{array}$ & \multicolumn{2}{|c|}{0.997} \\
\hline F- statistic & \multicolumn{2}{|c|}{1099.32} \\
\hline $\begin{array}{c}\text { Akaike info } \\
\text { criterion }\end{array}$ & \multicolumn{2}{|c|}{-5.67} \\
\hline $\begin{array}{c}\text { Log } \\
\text { likelihood }\end{array}$ & \multicolumn{2}{|c|}{79.01} \\
\hline
\end{tabular}

المصدر : نتـائج التحليـل من خلال بـرنامج Eviews .Ver"10" 
جدول 6. متوسط تكاليف إنتاج الفدان من محصول قصب السكر على مستوى الجمهورية خلال الفترة (2013(2018

\begin{tabular}{|c|c|c|c|c|c|c|c|}
\hline 2018 & 2017 & 2016 & 2015 & $* * 2014$ & 2013 & \multicolumn{2}{|c|}{ بنـود التكاليف (جنيه/فدان) } \\
\hline 434 & 394 & 357 & 368 & 318 & 268 & تحضير الأرض للزراعة & \\
\hline 2032 & 607 & 594 & 579 & 537 & 494 & التقاوى والزراعة & 司 \\
\hline 2309 & 1507 & 1257 & 1161 & 1082 & 1003 & 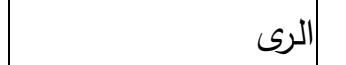 & 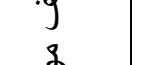 \\
\hline 2222 & 2132 & 1685 & 1603 & 1486 & 1369 & |التسميد & 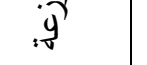 \\
\hline 539 & 363 & 416 & 422 & 390 & 357 & خقاومة الآفات & $\bar{y}$ \\
\hline 1414 & 836 & 667 & 613 & 574 & 534 & الحصاد أو الجنى & $\overline{3}$ \\
\hline 941 & 807 & 708 & 656 & 613 & 570 & نقل المحصول & , \\
\hline 1582 & 1064 & 909 & 864 & 800 & 735 & مصاريف أخرى & \\
\hline 11473 & 7710 & 6593 & 6266 & 5798 & 5330 & \multicolumn{2}{|c|}{ جملة التكاليف بدون إيجار } \\
\hline 5054 & $\begin{array}{c}2518 \\
-\end{array}$ & 2167 & 2230 & 2056 & 1882 & خدمة حيوانية & 司: \\
\hline 1515 & 1821 & 1579 & 1310 & 1202 & 1094 & خدمة آلية & .9 \\
\hline 1583 & 530 & 456 & 417 & 404 & 390 & ثمن تقاوى & $\bar{\jmath}$ \\
\hline 352 & 134 & - & 3 & 3 & 3 & ثمن سماد بلدى & j. \\
\hline 1387 & 1644 & 1482 & 1442 & 1334 & 1226 & ثمن سماد كيماوى & 青 \\
\hline 1582 & 1064 & 909 & 864 & 800 & 735 & مصاريف أخرى & i. \\
\hline 11473 & 7710 & 6593 & 6266 & 5798 & 5330 & \multicolumn{2}{|c|}{ جملة التكاليف بدون إيجار } \\
\hline 6875 & 6869 & 6858 & 2470 & 2365 & 2260 & & الإيجـار \\
\hline 18348 & 14579 & 13451 & 8736 & 8163 & 7590 & \multicolumn{2}{|c|}{ إجمـالى التكاليف بالإيجـار } \\
\hline 2013 & 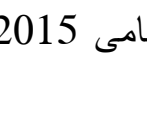 & بط لبيانات & 5201 & بيانات = & 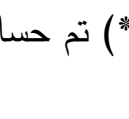 & نشرات. & إدراجها با \\
\hline
\end{tabular}


يُسـلاحظ من الجـــول حدوث حالة من التزايد المستمر

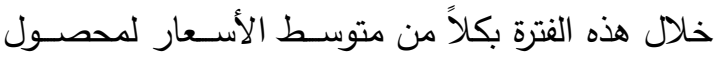

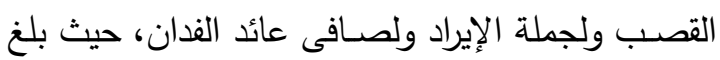

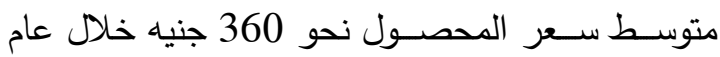
2013، ثم ارتفع خلال هذه الفترة حتى بلغ نحو 720

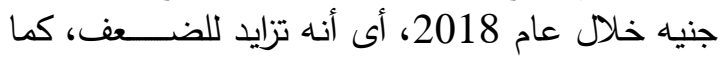

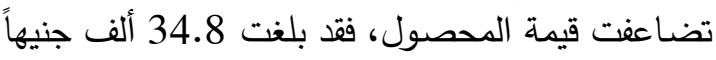
خلال عام 2018، بينما كانت تبلغ 17.3 ألف جنيهاً

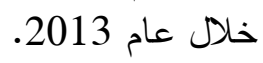

كنلك تزايد صافى عائد الفان من القصب بثكل مستمر خلال هذه الفترة، فقد بلغ 16.4 ألف جنيهاً خلال الندان عام 2018، بينما بلغ 9.7 ألف جنيهاً خلال عام .2013

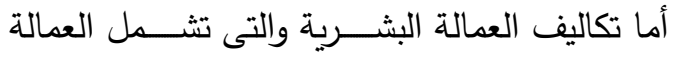
العائلية المبينة بالجدول، حيث يتضح أنها في حالة زيادة مستمرة خلال الفترة (2013- 2018)، وبالتالى حدوث التهاث

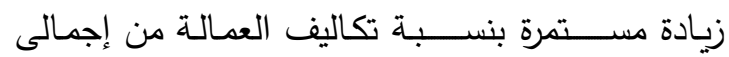

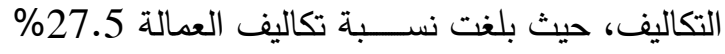

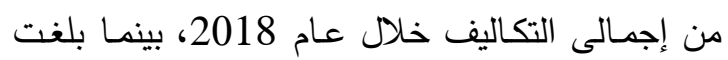

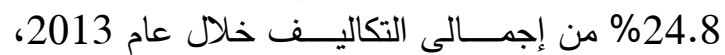

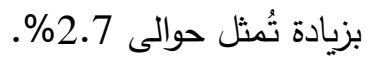

2-متوسط صافى عــــائد الفدان من محصول قصب السكر وتشير بيانات الجدول 7، إلى متوسط صافى عائد

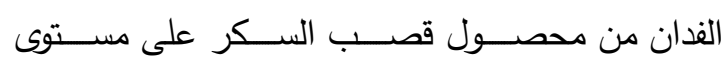

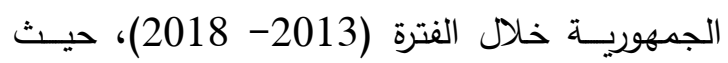

جدول 7. متوسط صافى عائد الفدان من محصول قصب السكر على مستوى الجمهورية خلال الفترة (2013(2018

\begin{tabular}{|c|c|c|c|c|c|c|c|c|c|c|}
\hline \multirow{2}{*}{$\begin{array}{l}\text { صائدى } \\
\text { الفدان } \\
\text { (جنيه) }\end{array}$} & \multirow{2}{*}{ اللتكاليفى } & \multirow{2}{*}{ الإيجار } & \multirow{2}{*}{ 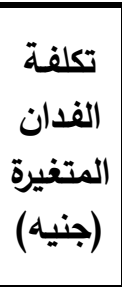 } & \multirow{2}{*}{ جمـلة الإيراد } & \multicolumn{2}{|c|}{ قيمـة المحصول } & \multicolumn{2}{|c|}{$\begin{array}{c}\text { متوسط الأسـعار (جنيه) } \\
\text { (جنيه }\end{array}$} & \multirow{2}{*}{ |إنتاج } & \multirow{2}{*}{ لالبـــــــان } \\
\hline & & & & & ثانوى | & رئيسى & | ثانوى | & رئيسى & & \\
\hline 9700 & 7590 & 2260 & 5330 & 17290 & - & 17290 & - & 360 & 48.028 & 2013 \\
\hline 10178 & 8163 & 2365 & 5798 & 18341 & - & 18341 & - & 380 & 48.36 & 2014 \\
\hline 10656 & 8736 & 2470 & 6266 & 19392 & - & 19392 & - & 400 & 47.48 & 2015 \\
\hline 15895 & 13451 & 6858 & 6593 & 29346 & - & 29346 & - & 620 & 47.332 & 2016 \\
\hline 19377 & 14579 & 6869 & 7710 & 33956 & - & 33956 & - & 720 & 47.161 & 2017 \\
\hline 16447 & 18348 & 6875 & 11473 & 34795 & - & 34795 & & 720 & 48.326 & 2018 \\
\hline
\end{tabular}


القصــب على مســتوى جمهورية مصــر العربية بأنهم

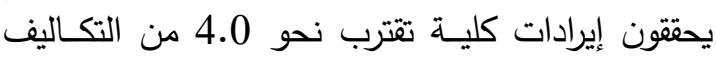
المتغيرة من إنتاج سكر القصب.

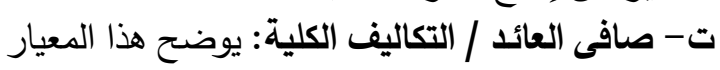

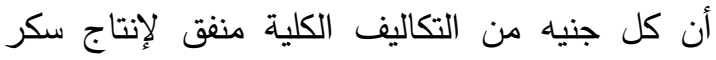
القصب يحقق صافى عائد بلغ حوالى 1.19.

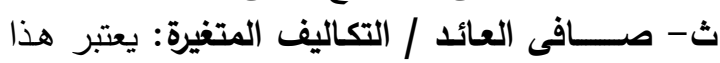

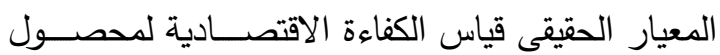

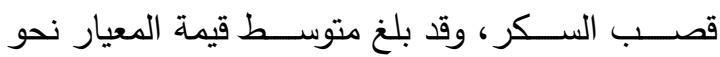

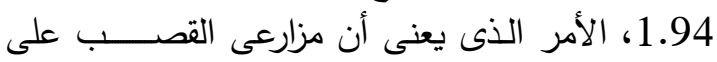

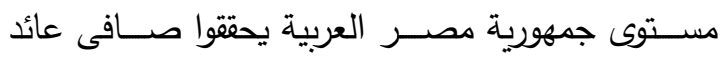

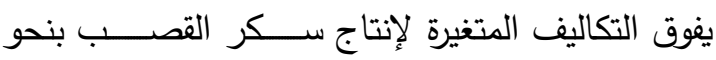
0.94 جنيه خلال الفترة (2013- 2018). ويتضح من مقاييس الكفاءة الاقتصادية لإنتاج سكر الفيه

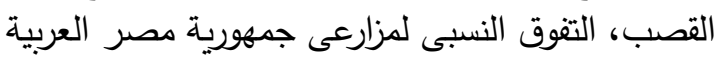

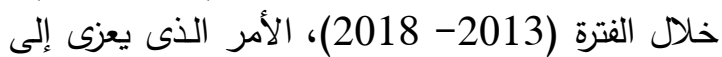

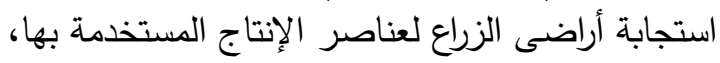

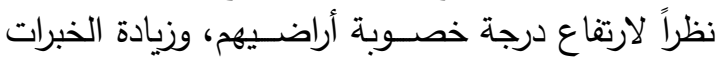

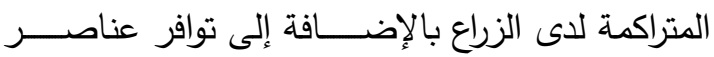
الإنتاج المستخدمة مثل التقاوى، والمبيدات، والأسمدة.
3- مؤشرات قياس الكفاءة الاقتصادية

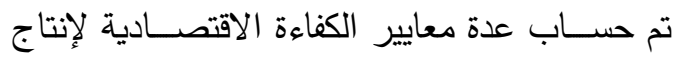

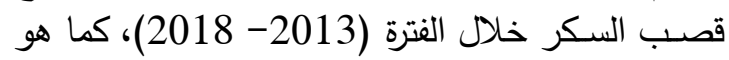
موضح بالجدول 8.

أ- الإيراد الكلى / التكاليف الكلية: يوضـح هذا المعيار

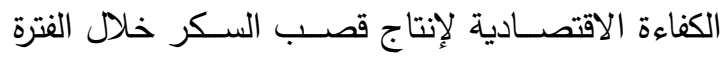

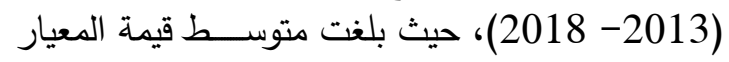

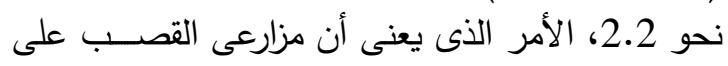

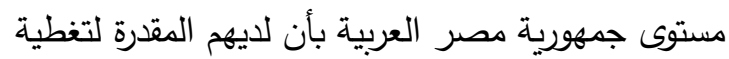
التكاليف وتحقيق فائض، وأن كل جنيه منفق فى إنتاج سكر القصب يحقق للمزارع فائض قُدر بنحو 1.2 جنيه خلال فترة الدراسة.

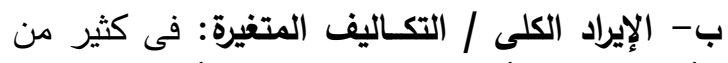

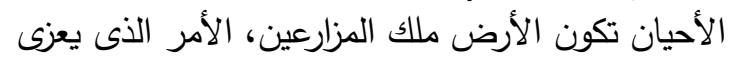

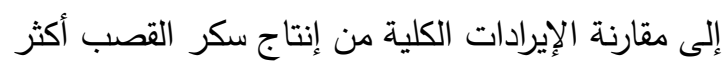

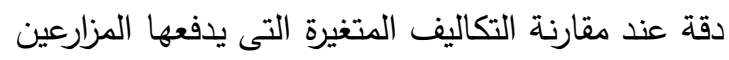

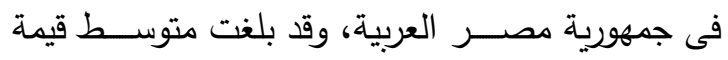

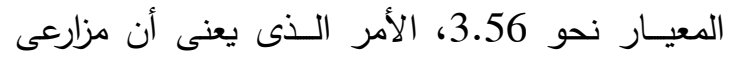

جدول 8. مؤشرات قياس الكفاءة الاقتصادية لإنتاج سكر القصب على مستوى جمهورية مصر العربية خلال الفترة (2018-2013)

\begin{tabular}{|c|c|c|c|c|}
\hline التكاليف المتغيرة & صافى العائدلاليف الكلية & التكاليفراد الكلى| & التكاليف الكلية & السنوات \\
\hline 1.82 & 1.28 & 3.24 & 2.28 & 2013 \\
\hline 1.76 & 1.25 & 3.16 & 2.25 & 2014 \\
\hline 1.70 & 1.22 & 3.09 & 2.22 & 2015 \\
\hline 2.41 & 1.18 & 4.45 & 2.18 & 2016 \\
\hline 2.51 & 1.33 & 4.40 & 2.33 & 2017 \\
\hline 1.43 & 0.90 & 3.03 & 1.90 & 2018 \\
\hline 1.94 & 1.19 & 3.56 & 2.19 & المتوسط \\
\hline
\end{tabular}

المصدر : جمعت وحسبت من: بيانات الجدول رقم (7). 


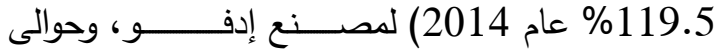

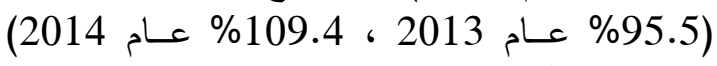
ل المصنع كوم أمبو. ووفقاً لأرقام متوسط الفترة (2016- 2018)، يتبين

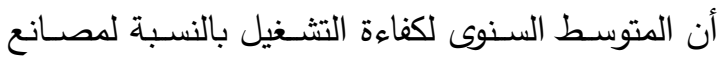

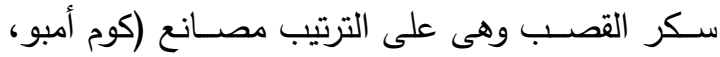

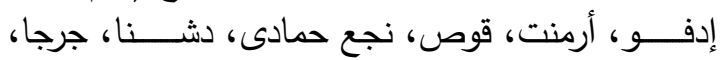

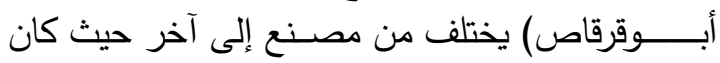

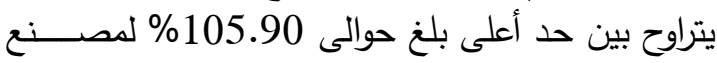

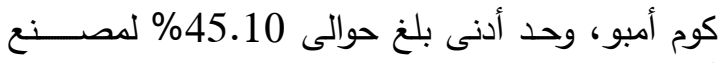

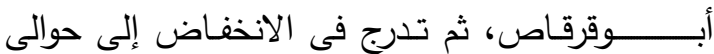

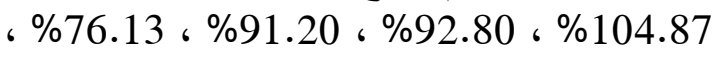

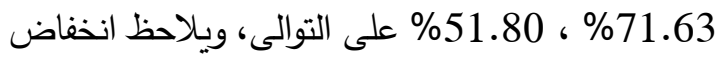

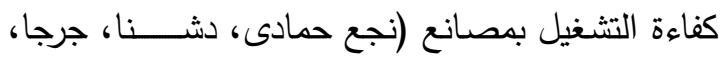

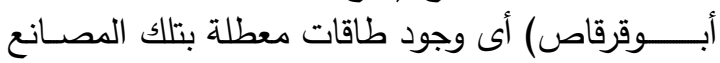

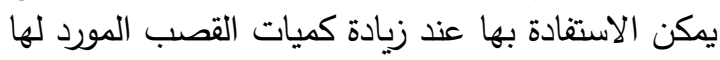

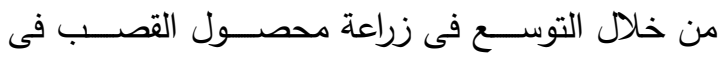

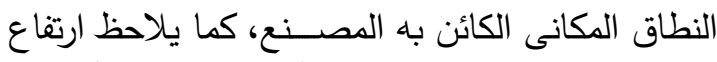

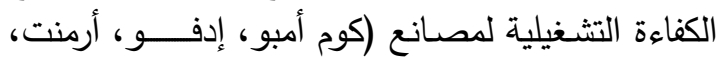

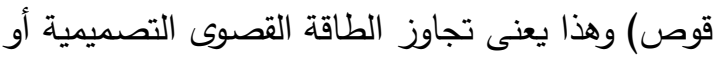
التشغيلية لتلك المصانع خلال نفس الطن الفترة.

خامساً: الأهميــة النسبية لوســـائل نــقل محصــــول القصب المُسـورد لمصــاتع السـكر خلال موسم عصير 2018 مقارنة بالموسم السابق 2017

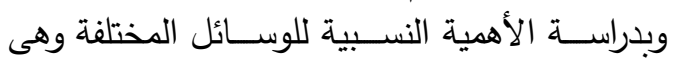

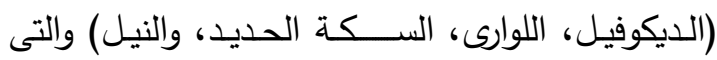

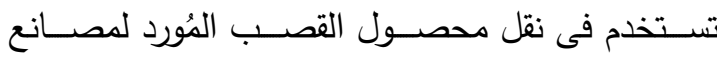

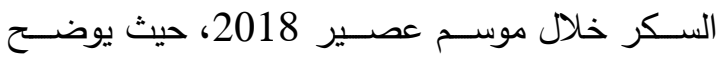

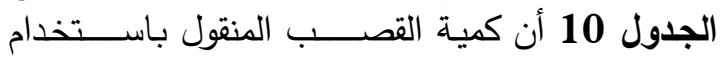

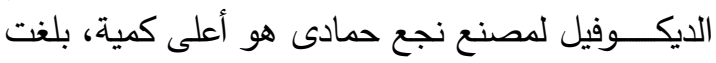

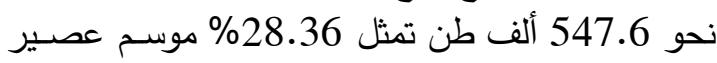

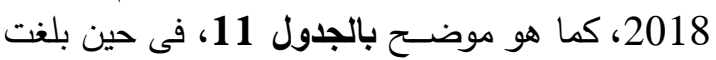

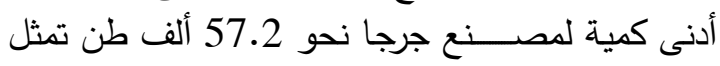

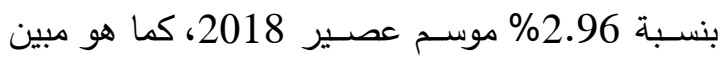

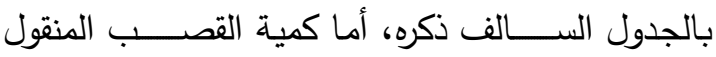

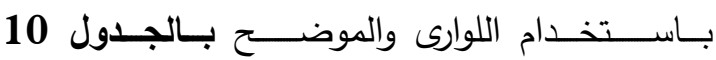

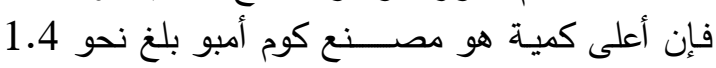

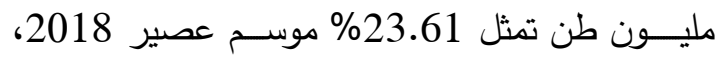

رابعـاً: تطور كفاءة التشغيل لمصانع سكر القصب فى المعاد

مصر خلال المواسم الإنتاجية (2013- 2018)

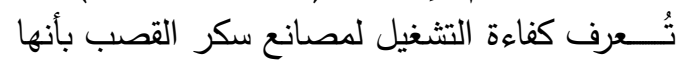

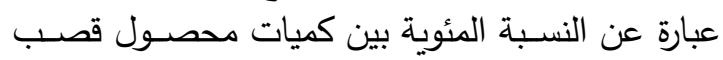

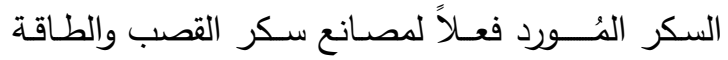
التصميمية لهذه المصانع، وهذه الكفـاءة قد تكون أقل

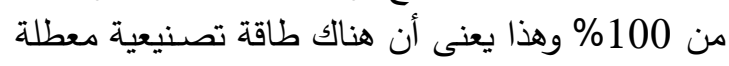

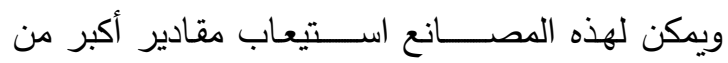

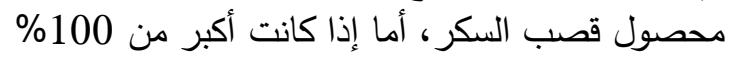

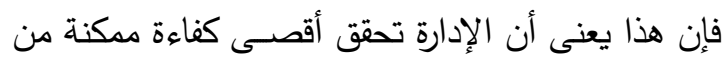

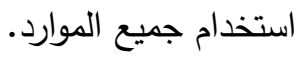

\section{$100 x$ كفاءة التشغيل لمصانع سكر القصب

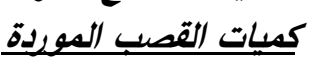 الطاقة التصميمية لمصانع سكر القصب}

توضح بيانات الجدول الـواردة رقم 9، تطور كفاءة

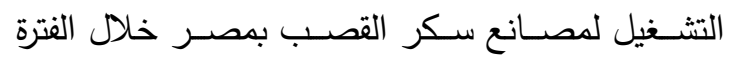

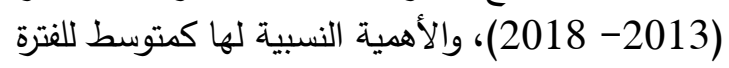
(2016- 2018)، حيث يتبين أن هذه الكفاءة بالنسبة

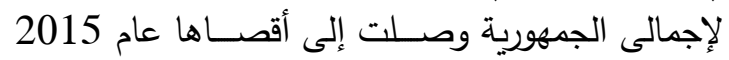

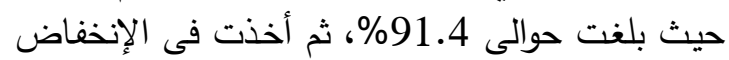

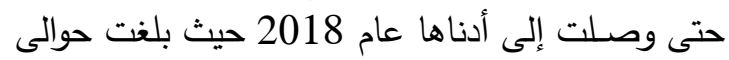

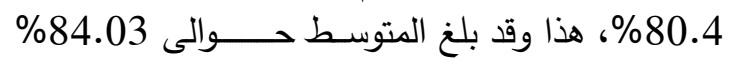
كتوسط للفترة (2016- 2018)، ويلاحظ ولخ انخفـاض

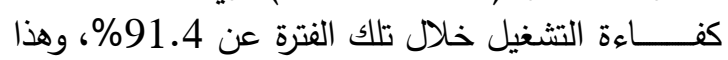

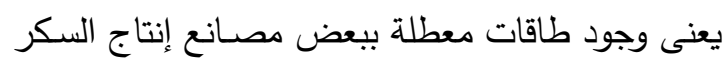

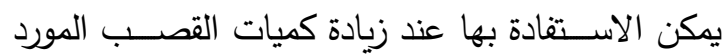
لها. أما بالنسبة لكفاءة التشغيل للمصانع الثمانية لسكر

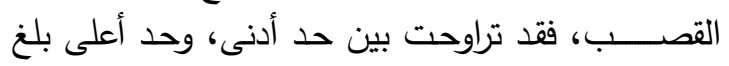

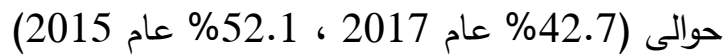

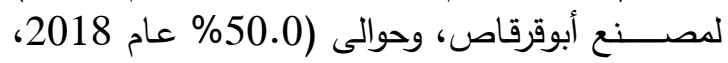

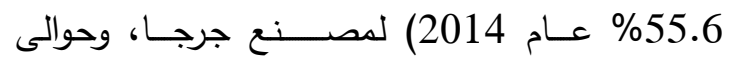

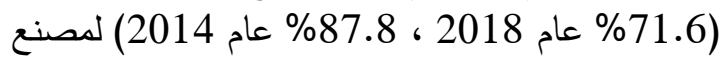

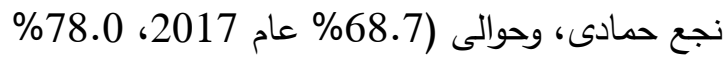

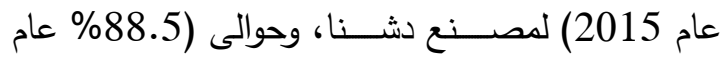

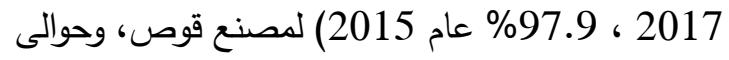

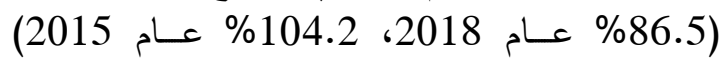
لمصــنع أرمنـت، وحوالى (57.1\% \% 2018، عـام 2018، 


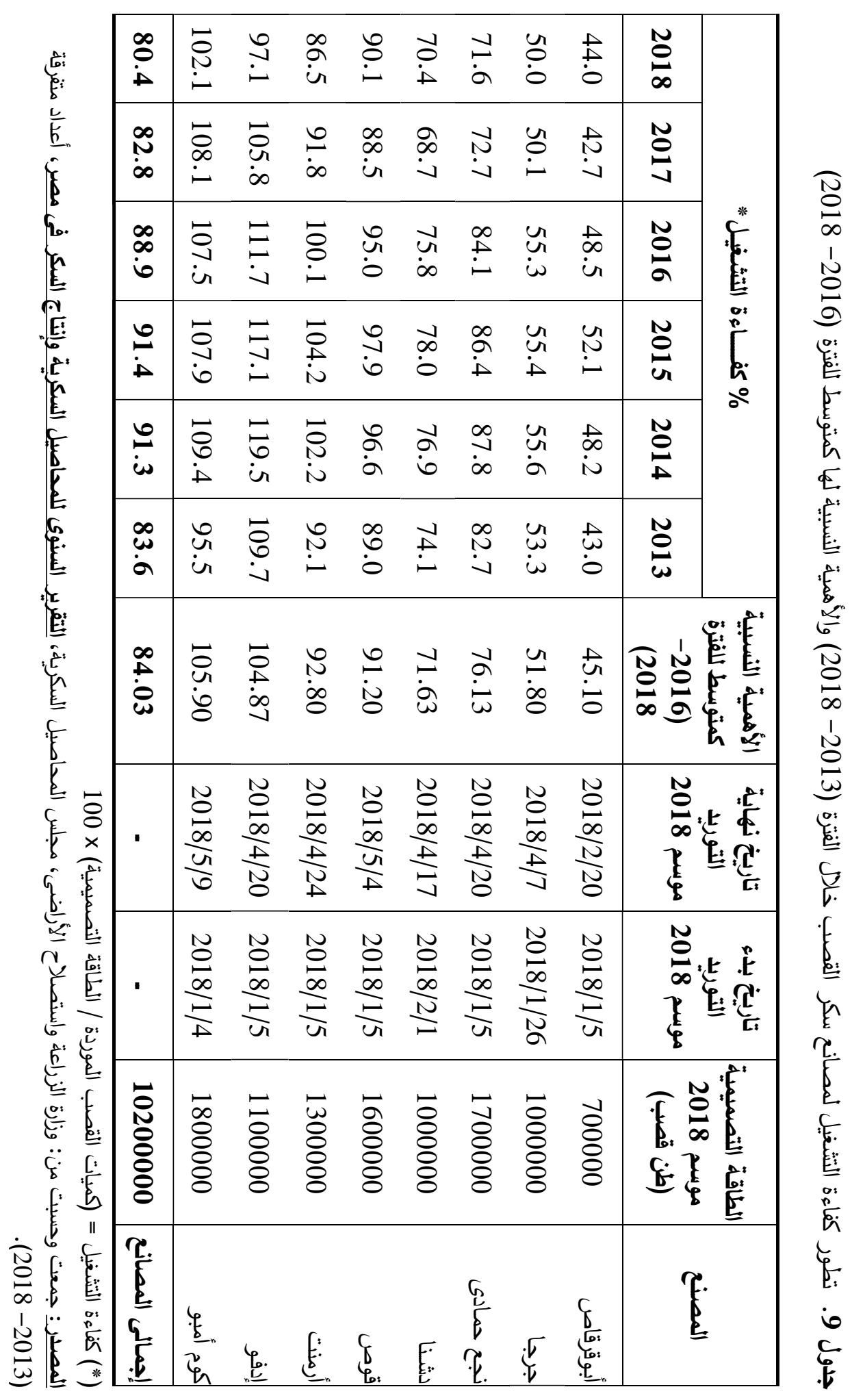




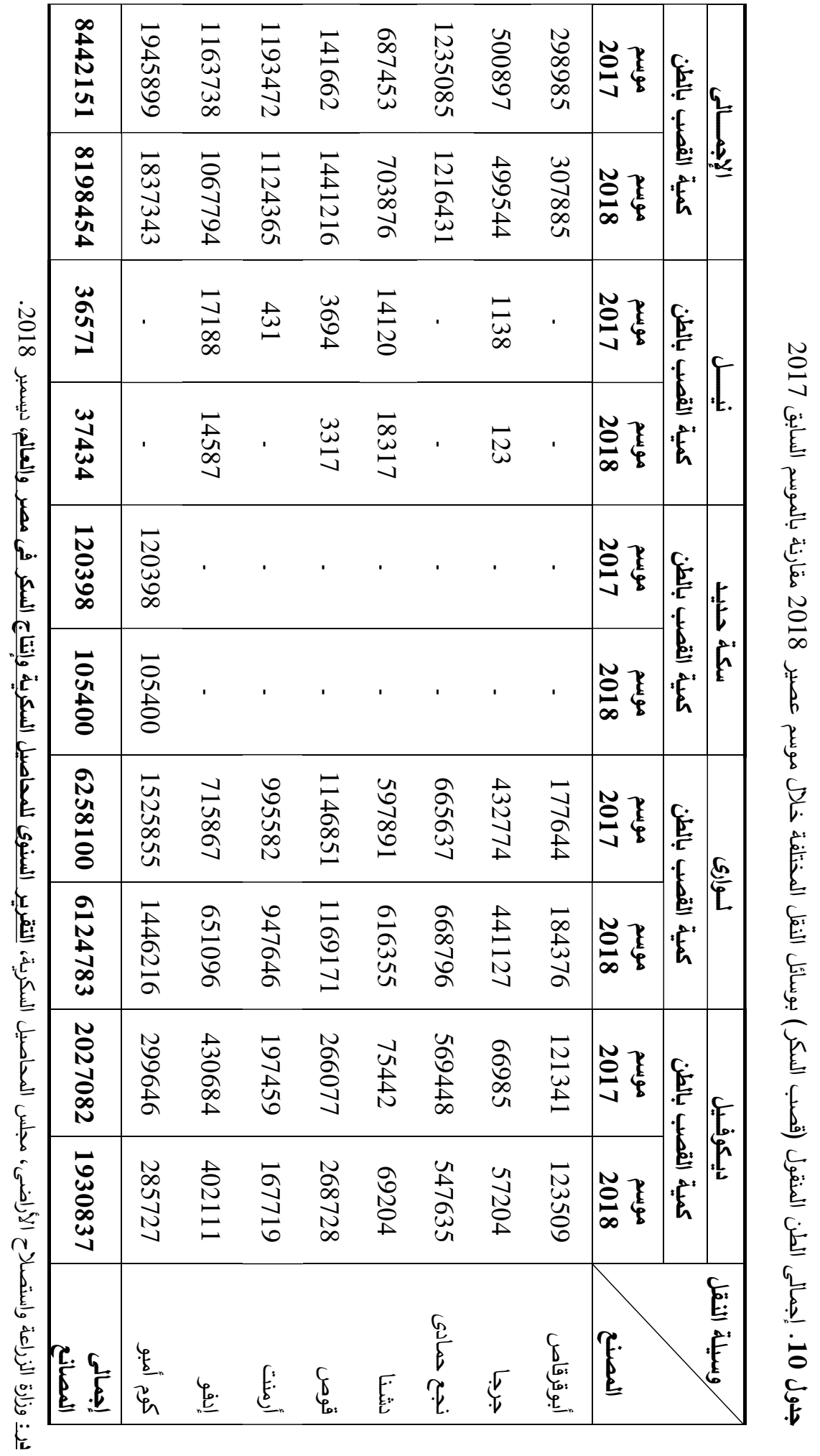




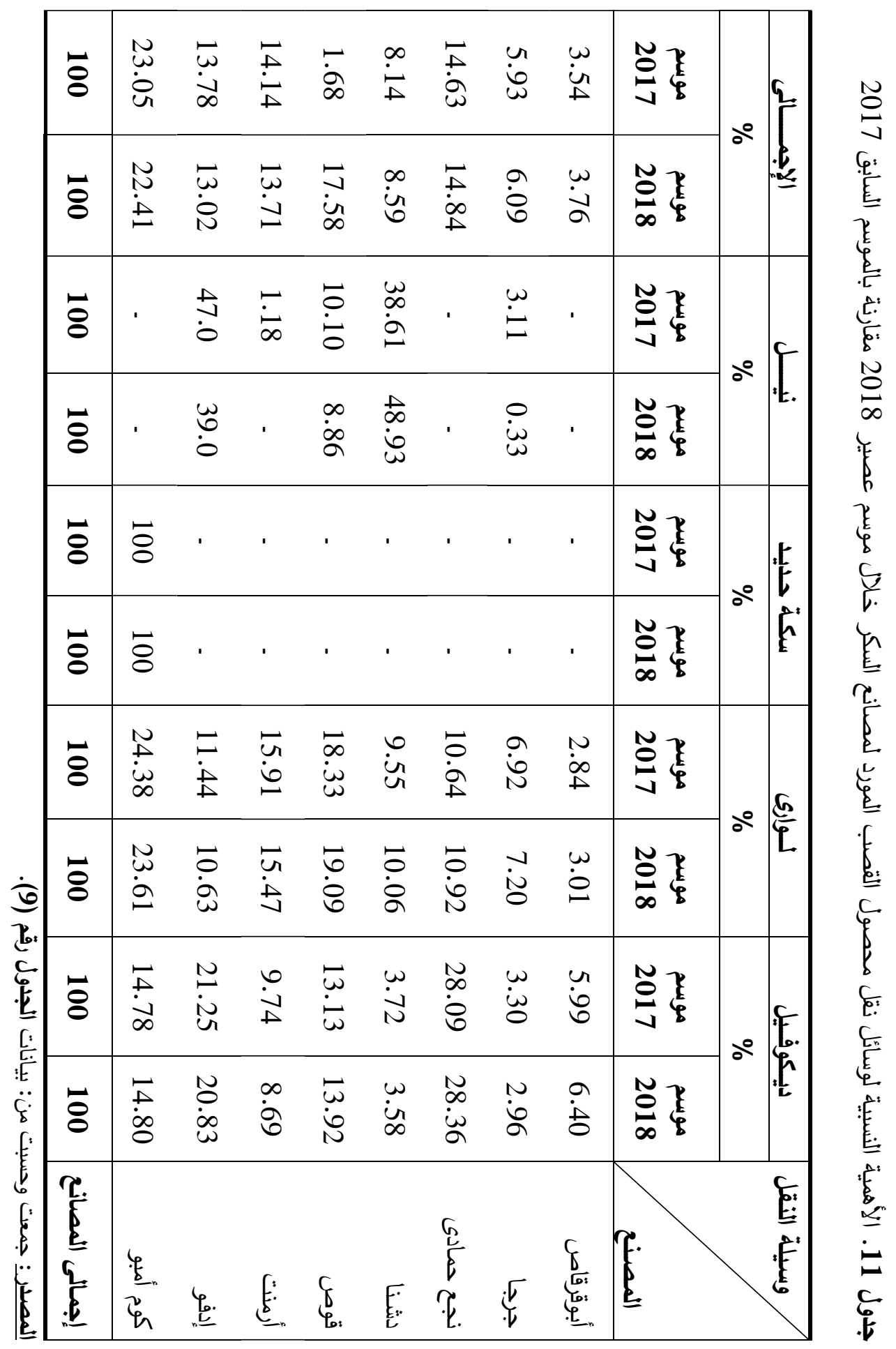


خلال موسم عصير 2017 مقارنة بموسم عصير 12 إندير 2017، يوضح الجدول 12 أن إجمالى كمية القصب لئب

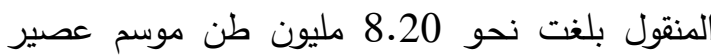

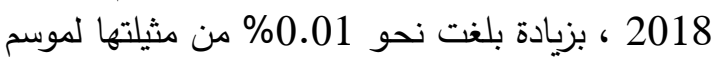

عصير 2017 ، كما هو موضح بالجدول 12. حيث أن نقل القصب المئورد لإجمالى الجئ المصانع لموسم عصير 2018 اعتمد بصورة رئيسية على 55.اللوارى، والديكوفيل بنسبة مئوية بلغت نحو 74.71\%

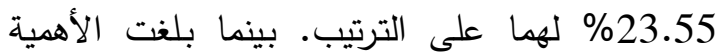
النسبية لاستخدام السكة الحديد، والنيل نحو 1.23\% 1.29\%، 0.46\% على الترتيب. مما يشير إلى زيادة الأهمية النسبية لاستخدام اللوارى، والنيل بنحو 0.03 عن موسم عصير 2017 على بلى الترتيب، وبانخفاض بلغ نحو 0.46\%، 0.14\% للديكوفيل،

والسكة الحديد على الترتيب.
كما هو مبين بالجدول 11، فى حين بلغت أدنى كمية

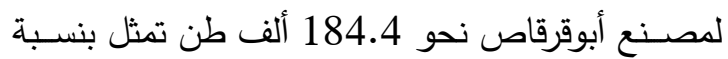

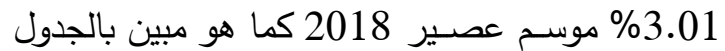

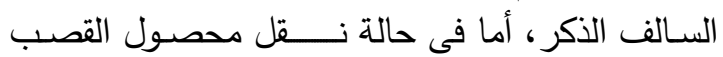

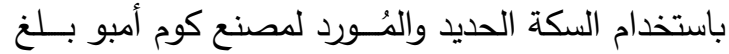

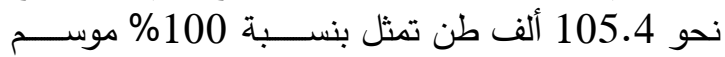

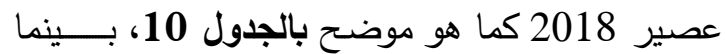
نلاحظ أن كمية القصب المنقول باستخدام النيل والمبين بالجدول 10، فإن أعلى كمية هو مصنع دشنا بلغ نحو النو

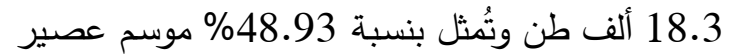

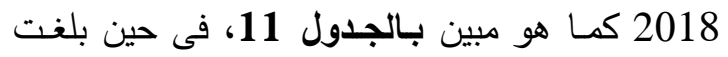

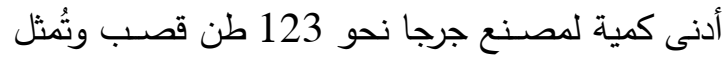

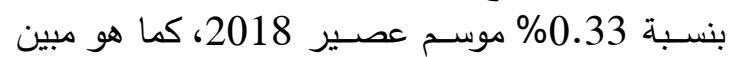

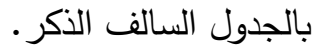
وبدراسة الأهمية النسبية للوسائل المختلفة المستخدمة فى نقل محصول القصب المُورد لإجمالى مصانع السكر الفيل

جدول 12. الأهمية النسبية لوسائل نقل محصول القصب الئورد لإجمالى مصانع السكر موسم عصير 2018 مقارنة بموسم عصير 2017

\begin{tabular}{|c|c|c|c|c|c|}
\hline \multirow{2}{*}{ مقدار التغير } & \multicolumn{2}{|c|}{ مـوسم عصير 2017} & \multicolumn{2}{|c|}{ مسوسم عصير 2018} & \multirow{2}{*}{ وسيلة النقل } \\
\hline & $\%$ & كمية القصب بالطن & $\%$ & كمية القصب بالطن & \\
\hline 0.58 & 74.13 & 6258100 & 74.71 & 6124783 & 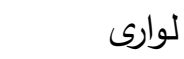 \\
\hline$(0.46)$ & 24.01 & 2027082 & 23.55 & 1930837 & ديكوفيل \\
\hline$(0.14)$ & 1.43 & 120398 & 1.29 & 105400 & سكة حديد \\
\hline 0.03 & 0.43 & 36571 & 0.46 & 37434 & 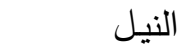 \\
\hline 0.01 & 100 & 8442151 & 100 & 8198454 & إجمالى عام \\
\hline
\end{tabular}

المصدر : جمعت وحسبت من: بيانات الجدول رقم (10). 


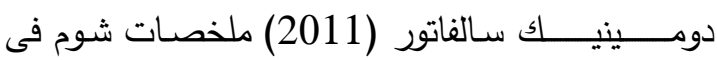
الإحصاء والاقتصاد القياسى، الدار الدولية للاستثمارات

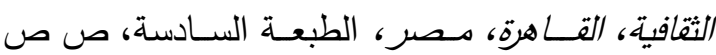
$.190-189$

شهيناز عيد محمود موسى (2006) بعض الإعتبارات

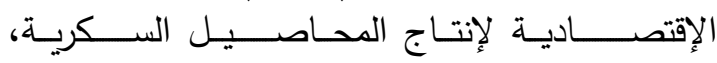
الجمعية المصـرية للاقتصـاد الزراعى، المجلة المصـرية الإسية للاقتصاد الزراعى، المجلد 16، 1187-1201. عبدالقادر محمـــــ عبدالقادر عطية (2000) الاقتصاد

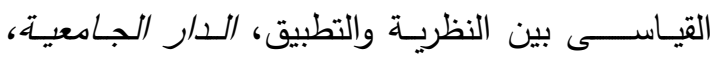
الإسكندرية، مصر، ص ص ص 317-328.

محمـد دسوقى إسماعيل حسين (2008) اقتصـاديـات

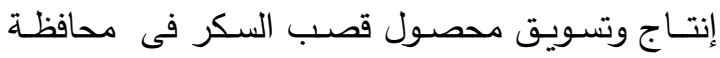

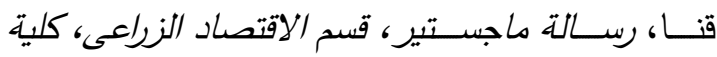

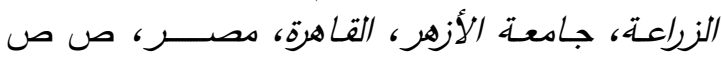
.156-147

محمد علاء الدين كامل عثمان ، محمود فرحان حسين الـين

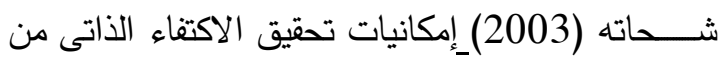

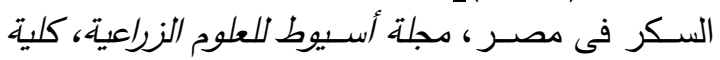

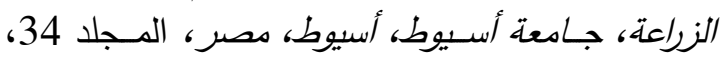
.327-310

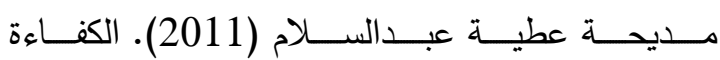

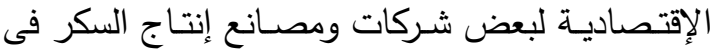

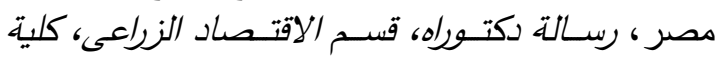

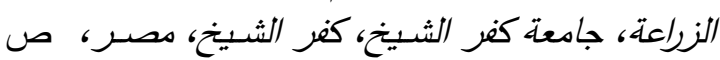

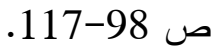

يحي شعبان يحي بخيت (2002) دراسة تحليلية لاقتصاديات إنتاج محاصيل السكر بدائرة مصنع

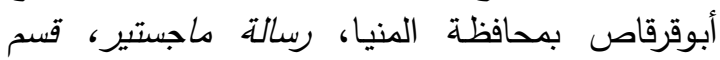

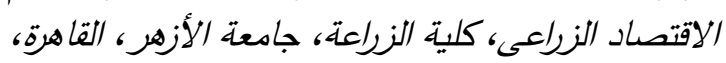
مصر، ص ص 106-124.

\section{5}

1) ضرورة دعم وتشجيع المنتجين على زيادة إنتاجية محصول قصب السكر ، وذلك باستتباط وزراعة أصناف جديدة عالية الإنتاجية. 2) ضرورة الاهتمام بمزراعي القصب، الإنتاجية أى تحسين

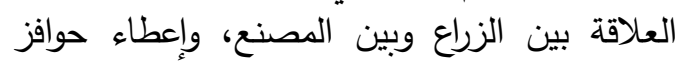

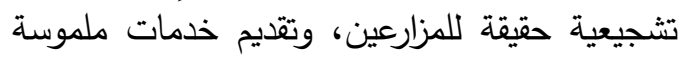

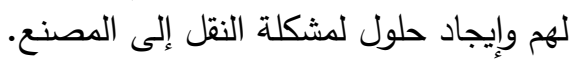

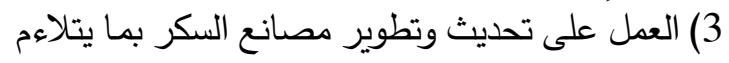
مع التطوير التكنولوجى لزيادة الكفاءة التشغيلية،

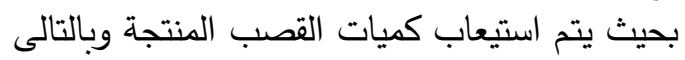

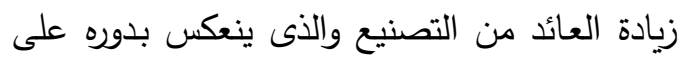
زيادة الكميات المنتجة من السكر محلياً.

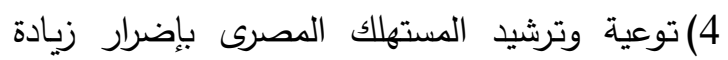

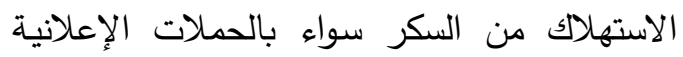

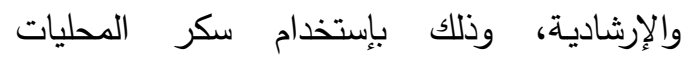

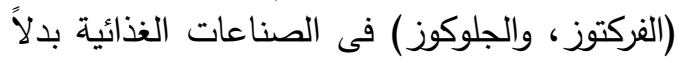
من سكر القصب. يجب وضع قانون جبرى (كالزراعة التعاقدية) لتوريد محصول قصب السكر وخاصة فى محافظات إنتاجه الرئيسية لضمان الوصول بالمصانع لأقصى كفاءة

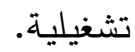

\section{المراجـع}

أمسين كمال السيد محمــد عنيبر (1998) اقتصاديات

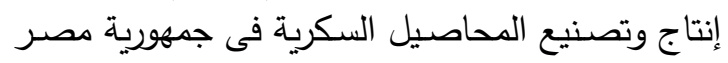

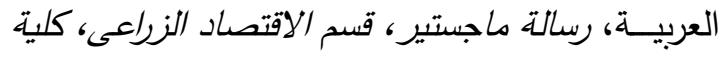

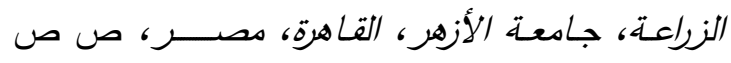
.169-140 


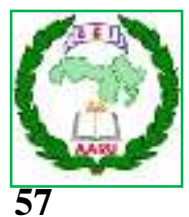

Arab Univ. J. Agric. Sci., Ain Shams Univ., Cairo, Egypt

29(1), 35-57, 2021

Website: http://ajs.journals.ekb.eg

DOI: 10.21608/ajs.2020.42469.1256

\title{
Econometric Analysis of the Cane Sugar Industry Determinants in Egypt
}

\author{
Karima MM Elsoghier*, Salwa MA Abdel-Monem, Mohamed S Shehata \\ Agricultural Economics Dept, Fac of Agric, Ain Shams Univ, P.O. Box 68, Hadayek \\ Shoubra 11241, Cairo, Egypt \\ *Corresponding author: dr.karima2020@gmail.com
}

Received 10 September, 2020

Accepted 20 February, 2021

\begin{abstract}
Sugar is an industrial agricultural commodity of strategic importance at the global level. At the local level, the sugar industry from the cultivation of sugar cane is considered an ancient industry that was supplemented by the manufacture of beets and the extraction of sugar from it. The research problem was represented in the existence of a sugar food gap estimated at 875.8 thousand tons of sugar as an annual average for the period (2000-2018). To fill this gap, the state imports sugar from abroad to meet the deficit. It is aimed study the current situation of the sugar industry in Egypt by analyzing the food gap for it and raise the rate of self-sufficiency in sugar. Then, the study was concerned with estimating the variables affecting each of the area and quantity of supplied cane, as well as the supply price, and the efficiency of sugar extraction on the function of the operating efficiency of cane sugar manufacturing factories in the main governorates (Minya, Sohag, Qena, Luxor, and Aswan), during the average period (20162018). Similarly, these variables affecting the aforementioned cane yield can be estimated on the function of the amount of sugar produced/operating day of the cane sugar factories in the governorates of Egypt during the same period, using the Panel Data analysis.
\end{abstract}

The most important results of the study revealed the following

1 - The results show that the variable $\ln x_{10 t}$ that expresses the average price of supplying a ton of cane during the study period is significant and has a negative sign, as shown in the model estimating the equation of the operational efficiency ratio, as an increase in the average price of supplying a ton of cane by $10 \%$ will lead to The operational efficiency decreased at a rate of about $3.11 \%$.

2 - It is also evident from the results of the model estimating the equation of the amount of sugar produced for one working day that the variable $\ln x_{6 t}$ that expresses the degree of sweetness of sugar produced from sugar manufacturing factories during the same period, it is significant and its sign is positive, as an increase in the degree of sugar sweetness by $1 \%$ will lead to an increase in quantities Sugar produced from manufacturing per day at a rate of about $19.6 \%$.

3 - It is clear from the measures of economic efficiency for the production of cane sugar, the relative superiority of farmers of the Arab Republic of Egypt during the period (2013-2018), which is attributed to the response of the farmers' lands to the production elements used in them, due to the high degree of fertility of their lands, and the increase in the accumulated experiences of the farmers.

Keywords: Sugarcane, Economic Efficiency, Plate Data Model, Operating Efficiency 